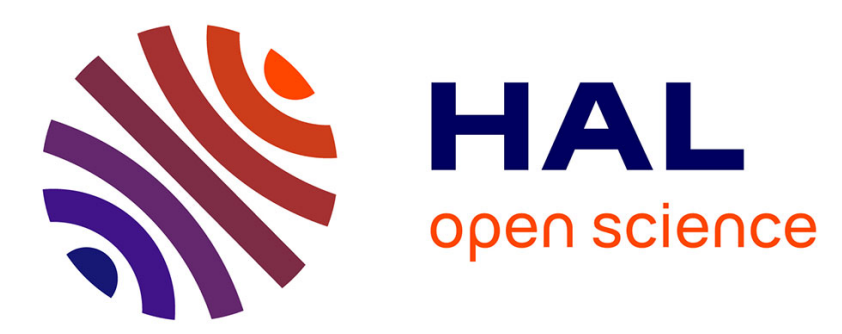

\title{
Experimental and modelling assessment of ductility in a precipitation hardening AlMgScZr alloy
}

Han Chen, Zhe Chen, G Ji, Shengyi Zhong, Haowei Wang, András Borbély, Yubin Ke, Yves Bréchet

\section{- To cite this version:}

Han Chen, Zhe Chen, G Ji, Shengyi Zhong, Haowei Wang, et al.. Experimental and modelling assessment of ductility in a precipitation hardening AlMgScZr alloy. International Journal of Plasticity, 2021, International Journal of Plasticity, 139, pp.102971. 10.1016/j.ijplas.2021.102971 . hal03370767

\section{HAL Id: hal-03370767 \\ https://hal.science/hal-03370767}

Submitted on 8 Oct 2021

HAL is a multi-disciplinary open access archive for the deposit and dissemination of scientific research documents, whether they are published or not. The documents may come from teaching and research institutions in France or abroad, or from public or private research centers.
L'archive ouverte pluridisciplinaire HAL, est destinée au dépôt et à la diffusion de documents scientifiques de niveau recherche, publiés ou non, émanant des établissements d'enseignement et de recherche français ou étrangers, des laboratoires publics ou privés. 


\title{
Experimental and modelling assessment of ductility in a precipitation hardening AlMgScZr alloy
}

\author{
Han Chen ${ }^{\mathrm{a}}$, Zhe Chen ${ }^{\mathrm{a}^{*}}$, Gang Ji ${ }^{\mathrm{b}}$, Shengyi Zhong ${ }^{\mathrm{c}^{*}}$, Haowei Wang ${ }^{\mathrm{a}}$, András Borbély ${ }^{\mathrm{d}}$, Yubin \\ $\mathrm{Ke}^{\mathrm{e}}$, Yves Bréchet ${ }^{\mathrm{c}, \mathrm{f}}$ \\ a State Key Laboratory of Metal Matrix Composites, Shanghai Jiao Tong University, Shanghai 200240, PR China \\ b Univ. Lille, CNRS, INRAE, Centrale Lille, UMR 8207 - UMET - Unité Matériaux et Transformations, F-59000 \\ Lille, France \\ ${ }^{\mathrm{c}}$ School of Materials Science and Engineering, Shanghai Jiao Tong University, Shanghai 200240, PR China \\ d Univ. Lyon, IMT Mines Saint-Etienne, Centre SMS, CNRS, LGF, F - 42023 Saint-Etienne France \\ e Spallation Neutron Source Science Center, Institute of High Energy Physics, Chinese Academy of Sciences, \\ Dongguan 523803, China \\ ${ }^{\mathrm{f}}$ Université Grenoble Alpes, SIMAP, 38000 Grenoble, France \\ *Corresponding authors: Dr. Zhe Chen (zhe.chen@sjtu.edu.cn); Dr. Shengyi Zhong (shengyi.zhong@sjtu.edu.cn)
}

\begin{abstract}
Precipitation hardening is the most effective strategy to enhance the mechanical properties of metals. Dislocation mechanisms to control strengthening during precipitation have been demonstrated extensively. However, owing to the complexity of different precipitates in alloys, variations in ductility caused by precipitation are complex and have not been clarified so far. In this study, the effects of precipitation on ductility in precipitation hardening aluminium alloys are investigated based on a modified dislocation-based approach and experimental characterisation. The $\mathrm{AlMgScZr}$ alloy with spherical $\mathrm{Al}_{3}(\mathrm{Sc}, \mathrm{Zr})$ precipitates is used as a model alloy system to understand the effects of precipitation on ductility. Via heat treatment, shearable and nonshearable $\mathrm{Al}_{3}(\mathrm{Sc}, \mathrm{Zr})$ precipitates are introduced in the $\mathrm{AlMg}$ matrix. The results show that the ductility of AlMgScZr alloy decreases when shearable precipitates occur, while it increases with shearable precipitates being replaced by nonshearable precipitates. The variation in ductility of AlMgScZr alloy is mainly controlled by the dynamic recovery rate of the dislocations. Finally, by analysing the different precipitate-dislocation interactions and evaluating the dislocation density evolution during deformation, the dislocation mechanisms of
\end{abstract}


ductility during precipitation for AlMgScZr alloy are demonstrated. This study reveals the dislocation mechanism for controlling ductility during precipitation for $\mathrm{AlMgScZr}$ alloy which can provide a theoretical foundation for the design of high-performance structural materials.

Keywords: Ductility; precipitates; dislocations; a dislocation-based approach; modelling

\section{Introduction}

Lightweight design strategies and advanced energy applications are the requirement for next-generation high-performance structural materials. Improving the strength of lightweight aluminium or other alloys via nanosized precipitates or nanoparticles is an effective and low-cost method [Kim et al., 2015; Jiang et al., 2017; Wu et al., 2017; Lei et al., 2018; Yang et al., 2018; Sun et al., 2019] which has received extensive attention in recent decades [Ardell, 1985; Gladman, 1999; Kendig and Miracle, 2002; Zhao et al., 2006; Fazeli et al., 2008; Hull and Bacon, 2011; Xu et al., 2019; Zhang et al., 2020]. Over the past decades, extensive research has shown that precipitates can clearly increase the strength of aluminium or other alloys [Ardell, 1985; Gladman, 1999; Kendig and Miracle, 2002; Zhao et al., 2006; Fazeli et al., 2008; Teixeira et al., 2009; Knipling et al., 2010; Hull and Bacon, 2011; Ding et al., 2018; Fan et al., 2018; Luca et al., 2019; Xu et al., 2019; Zhang et al., 2020]. The above studies mainly focused on maximising strength to the extent possible by optimising heat treatment parameters. Generally, precipitation strengthening is attributed to the interaction of precipitates and dislocations [Ardell, 1985; Gladman, 1999; Kendig and Miracle, 2002; Zhao et al., 2006; Hull and Bacon, 2011]. The well-known interaction mechanisms between precipitates and dislocations are shearing and Orowan bypassing mechanisms [Ardell, 1985; Gladman, 1999; Knipling et al., 2010; Hull and Bacon, 2011; Fan et al., 2018; Ming et al., 2018]. When the average size of the precipitate is small (for shearable precipitates), the dominant 
interaction mechanism is dislocation shearing [Ardell, 1985; Gladman, 1999; Knipling et al., 2010; Hull and Bacon, 2011; Fan et al., 2018; Ming et al., 2018]. With increasing precipitate size (for nonshearable precipitates), the interaction mechanism is primarily dominated by the Orowan bypassing mechanism [Ardell, 1985; Gladman, 1999; Knipling et al., 2010; Hull and Bacon, 2011; Fan et al., 2018; Ming et al., 2018]. Based on the different precipitate-dislocation interactions, several successful models have been proposed to describe the variation in strength during precipitation in precipitation hardening alloys [Ardell, 1985; Gladman, 1999; Knipling et al., 2010; Hull and Bacon, 2011; Ma et al., 2014; Fan et al., 2018]. However, the physical mechanisms of ductility during precipitation are complex and have not been investigated sufficiently to date.

The ductility of materials is usually considered as tensile plasticity, which is measured by tensile test only. Most current studies on ductility can be mainly divided into two categories. One group of researchers have demonstrated that the ductility includes uniform elongation (before necking point) and non-uniform elongation (after necking point to failure) [Kim and Estrin, 2001; Liu et al., 2005; Huang et al., 2006; Koch et al., 2013; Kim et al., 2015; Wu and Curtin, 2015; Li et al., 2016; Li et al., 2017b; Ovid'ko et al., 2018; Wu et al., 2018]. The other group of researchers attribute ductility to the uniform elongation [Zhao et al., 2006; Liu et al., 2013; Wu et al., 2015; Li et al., 2017a; Huang et al., 2018; Lei et al., 2018; Ovid'ko et al., 2018; Shao et al., 2018; Yang et al., 2018; Yang et al., 2019; Zhang et al., 2019]. It has been reported that the uniform elongation is not affected much by the specimen size or geometry [Zhao et al., 2008; Zhao et al., 2009; He et al., 2017; Ovid'ko et al., 2018], which is more suitable for the determination of ductility of materials. Besides, the non-uniform elongation falls under the scope of plastic instability which is a very complex process (also associated with the nucleation and propagation of microvoids or microcracks [Li et al., 2016; Ovid'ko et al., 2018]). In this study, we mainly reveal the dislocation mechanisms of uniform elongation (before the necking point) that causes ductility.

The classic Considère and Hart criteria are mainly used to estimate the instability caused by necking for strain rate insensitive and strain rate sensitive materials, 
respectively [Considère, 1885; Hart, 1967]. According to the Considère and Hart criteria, a higher work hardening rate could suppress the necking point and promote a higher ductility [Wang et al., 2002; Zhao et al., 2006; Lei et al., 2018; Yang et al., 2018; Yang et al., 2019]. In addition, some studies have demonstrated that ductility is controlled by the strain rate sensitivity for some alloys [Ghosh, 1977; Hutchinson, 1977; Wang and Ma, 2004]. However, all the aforementioned studies (based on Considère and Hart criteria) follow mechanistic approaches and do not consider any intrinsic microscopic features and variables associated with dislocation evolution. Yasnikov et al. [Yasnikov et al., 2014, 2017; Vinogradov et al., 2016] proposed a dislocation-based approach to predict the ductility variation in metals ranging from coarse- to ultrafine-grained microstructures. They demonstrated the dependence of ductility on the dislocation behaviours and history of metal pre-processing. Motivated by these studies, we propose a modified dislocation-based approach to explain ductility during precipitation via experimental characterisation.

Shearable and nonshearable $\mathrm{Al}_{3}(\mathrm{Sc}, \mathrm{Zr})$ precipitates with excellent thermal stability, spherical shape, and uniform spatial distribution can be obtained by controlling the heat treatment parameters [Fuller et al., 2003; Voorhees, 2006; Knipling et al., 2010]. In addition, owing to their excellent qualities, these precipitates can be quantitatively characterised via transmission electron microscopy (TEM) and small angle neutron scattering (SANS) [Perrard et al., 2006; Decreus et al., 2013]. Therefore, $\mathrm{Al}_{3}(\mathrm{Sc}, \mathrm{Zr})$ precipitate is used as a model precipitate to investigate the variation in ductility of the metals during precipitation. In the present study, we use $\mathrm{AlMgScZr}$ as the model alloy system. The advantage of AlMgScZr is that the solute concentration (the solute concentration of $\mathrm{Sc}$ and $\mathrm{Zr}$ is very small, and its change during precipitation can be omitted compared with $\mathrm{Mg}$ element) remains almost unchanged during precipitation which can probably nullify the effects of solute concentration variation on ductility during precipitation. Dislocation-based processes govern the plastic deformation of metals. During these processes, the strength and ductility of metals can be altered, as reported recently [Zhao et al., 2006; Kim et al., 2015; Jiang et al., 2017; Yang et al., 2018; Zhang et al., 2019]. Introducing nanosized 
precipitates or nanoparticles can result in a better combination of strength and ductility by mediating intrinsic dislocation behaviours [Zhao et al., 2006; Kim et al., 2015; Jiang et al., 2017; Yang et al., 2018]. In this study, the dislocation mechanism for controlling ductility during precipitation for $\mathrm{AlMgScZr}$ alloy can be understood on the basis of dislocation-precipitate interactions. This provides important insight into designing alloy systems with enhanced mechanical properties.

\section{Experiments and methods}

The matrix metal used is $\mathrm{AlMg}$ alloy; therefore, the designed alloy here is AlMgScZr. The used materials were all produced by direct chill casting with pure $\mathrm{Al}$ (99.999\%), Al-2\%Sc master alloy, Al-10\%Zr master alloy, and pure Mg (99.99\%). The nominal chemical compositions of designed AlMg and AlMgScZr alloys are $\mathrm{Al}-6 \% \mathrm{Mg}$ (wt.\%) and $\mathrm{Al}-6 \% \mathrm{Mg}-0.2 \% \mathrm{Sc}-0.15 \% \mathrm{Zr}$ (wt.\%), respectively. The chemical compositions of the cast AlMg and AlMgScZr alloys, determined by inductively coupled plasma mass spectrometry (ICP-MS), were Al-5.7\% Mg (wt.\%) and $\mathrm{Al}-5.4 \% \mathrm{Mg}-0.2 \% \mathrm{Sc}-0.15 \% \mathrm{Zr}$ (wt.\%), respectively. The cast AlMg alloy was directly extruded at $623 \mathrm{~K}$ with an extrusion ratio of 10:1. The cast AlMgScZr alloys were first aged at $623 \mathrm{~K}$ for $3 \mathrm{~h}$ (labelled with Alloy-S) and at $813 \mathrm{~K}$ for $24 \mathrm{~h}$ (labelled with Alloy-NS), followed by water quenching. These aged alloys were extruded at $623 \mathrm{~K}$ with an extrusion ratio of 10:1. As the extrusion temperature is lower than the ageing temperature, the $\mathrm{Al}_{3}(\mathrm{Sc}, \mathrm{Zr})$ precipitate formed during ageing does not coarsen during the extrusion process.

The quantitative characterisation of the precipitate was conducted by TEM and SANS. The samples for TEM were first mechanically polished to $80 \mu \mathrm{m}$, followed by electrochemical polishing using a twin-jet polishing unit with a mixed solution of $33.3 \%$ methanol and $66.6 \%$ nitric acid at $22 \mathrm{~V}$ and $233 \mathrm{~K}$. TEM observations were conducted using a JOEM-2100F operating at $200 \mathrm{kV}$ and a high-resolution Cs-corrected FEI $\operatorname{Titan}^{3}$ Themis at $300 \mathrm{kV}$. SANS was performed on a small angle neutron scattering instrument at the China Spallation Neutron Source $[\mathrm{Ke}$ et al., 
2018].

The tensile tests were conducted at room temperature with a strain rate of $5 \times 10^{-2}$ $-5 \times 10^{-5} \mathrm{~s}^{-1}$. The gage section of the tensile specimens with dog-bone shape was $15 \times$ $3 \times 2 \mathrm{~mm}^{3}$. The dislocation densities of the AlMg and AlMgScZr alloys were determined by high-resolution X-ray diffraction line profile analysis, which were measured by synchrotron radiation X-ray diffraction at beamline BL14B1 in the Shanghai Synchrotron Radiation Facility [Yang et al., 2015]. A monochromatic X-ray beam with an energy of $18 \mathrm{keV}$ (with wavelength $0.06889 \mathrm{~nm}$ ) and a beam size of $180 \mu \mathrm{m}$ (width) $\times 200 \mu \mathrm{m}$ (height) was used. The diffractometer was equipped with a double crystal monochromator and had negligible instrumental broadening (less than $0.001^{\circ}$ ). The range of diffraction angle is about $7.5 \sim 19.0^{\circ}$, during which the (111), (200), (220), (311) and (222) peaks of aluminum matrix were detected. The Mythen $1 \mathrm{~K}$ linear detector was adapted for high resolution diffraction data acquisition in Debye-Sherrer mode, and the exposure time was $5 \mathrm{~s}$. The wavelength of the X-ray was calibrated using $\mathrm{LaB}_{6}$ standard from NIST(660b). The average dislocation density is determined by analysing the asymptotic behaviour of the second-order and fourth-order restricted moments using the restricted moment method [Borbély and Groma, 2001]. We mention that the momentum method based on the asymptotic behaviour of the intensity distribution is the most accurate among the available approaches [Borbély and Ungár, 2012]. Since the full width at half maximum of the peaks depends on the spatial distribution of dislocations [Kalácska et al., 2017] simpler methods such as the modified Williamson-Hall [Ungár and Borbély, 1996] or any of their variants are highly discouraged to use.

\section{Results and analysis}

\subsection{Quantitative characterisation of precipitates}

The characterisation of the precipitates is conducted using TEM and scanning transmission electron microscopy (STEM). Fig. 1 shows the dark-field TEM images of $\mathrm{Al}_{3}(\mathrm{Sc}, \mathrm{Zr})$ precipitates for the Alloy-S and Alloy-NS samples. As shown in the 
figure, the spherical-shaped $\mathrm{Al}_{3}(\mathrm{Sc}, \mathrm{Zr})$ precipitates are homogeneously distributed in the AlMg matrix for both samples. Fig. 2 shows the STEM of small $\mathrm{Al}_{3}(\mathrm{Sc}, \mathrm{Zr})$ precipitates obtained from the Alloy-S sample. The precipitate size is about several nanometres in diameter (Fig. 2 (a)). The inverse fast Fourier transformation (IFFT) images in Figs. 2 (g) and (h) show that the small precipitates are completely coherent with the matrix. Fig. 3 shows the STEM of a large $\mathrm{Al}_{3}(\mathrm{Sc}, \mathrm{Zr})$ precipitate obtained from the Alloy-NS sample. Further, the size of the precipitate is approximately $20 \mathrm{~nm}$ in diameter (Fig. 3 (a)). No misfit dislocations are observed at the interface of large precipitates and matrix (Figs. $3(\mathrm{~d}-\mathrm{e})$ ), indicating a fully coherent interface. The results in Figs. 1, 2, and 3 indicate that both the small and large precipitates have the same morphology, distribution, and interface structure.
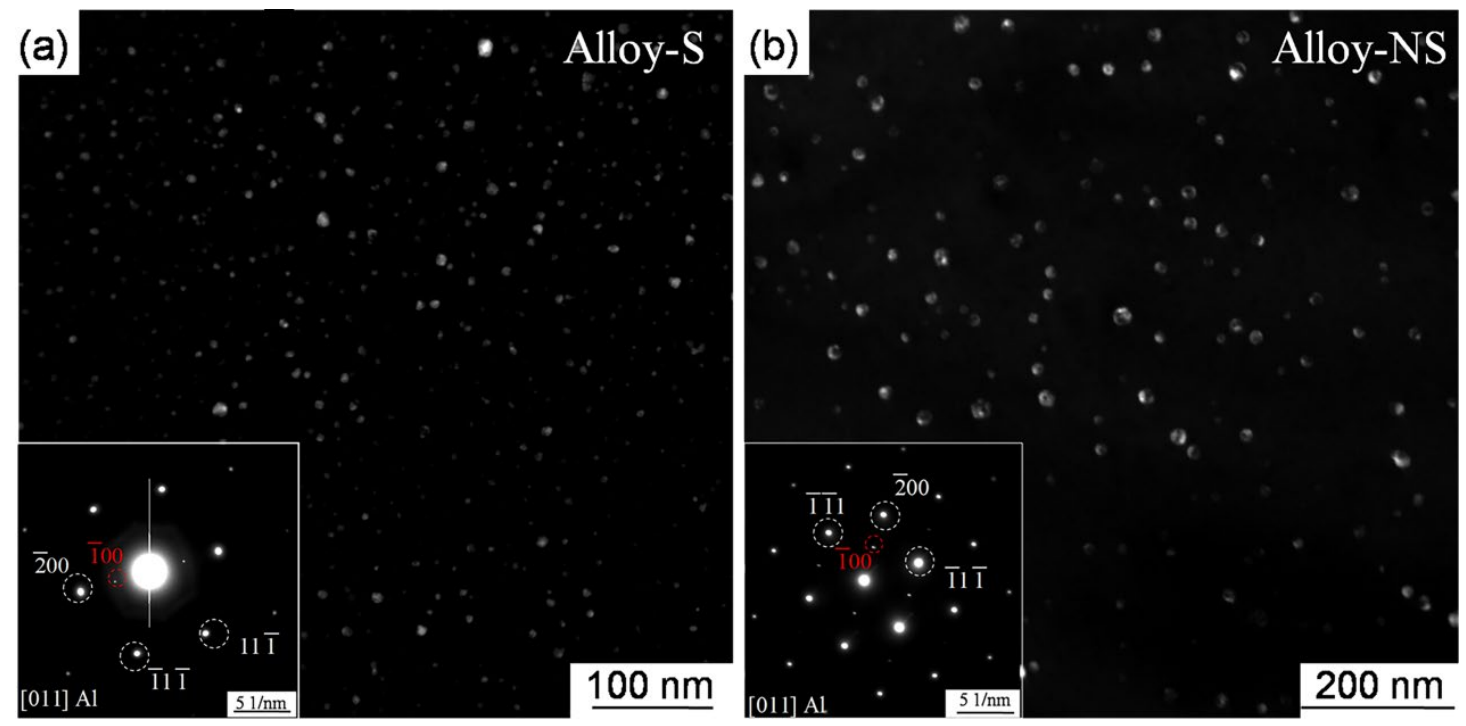

Fig. 1 Quantitative characterisation of the precipitates: (a) and (b) dark-field TEM images of the Alloy-S sample (made with the -100 diffraction spot) and the Alloy-NS sample (made with the -100 diffraction spot), respectively. The inset figures correspond to selected area electron diffraction. 

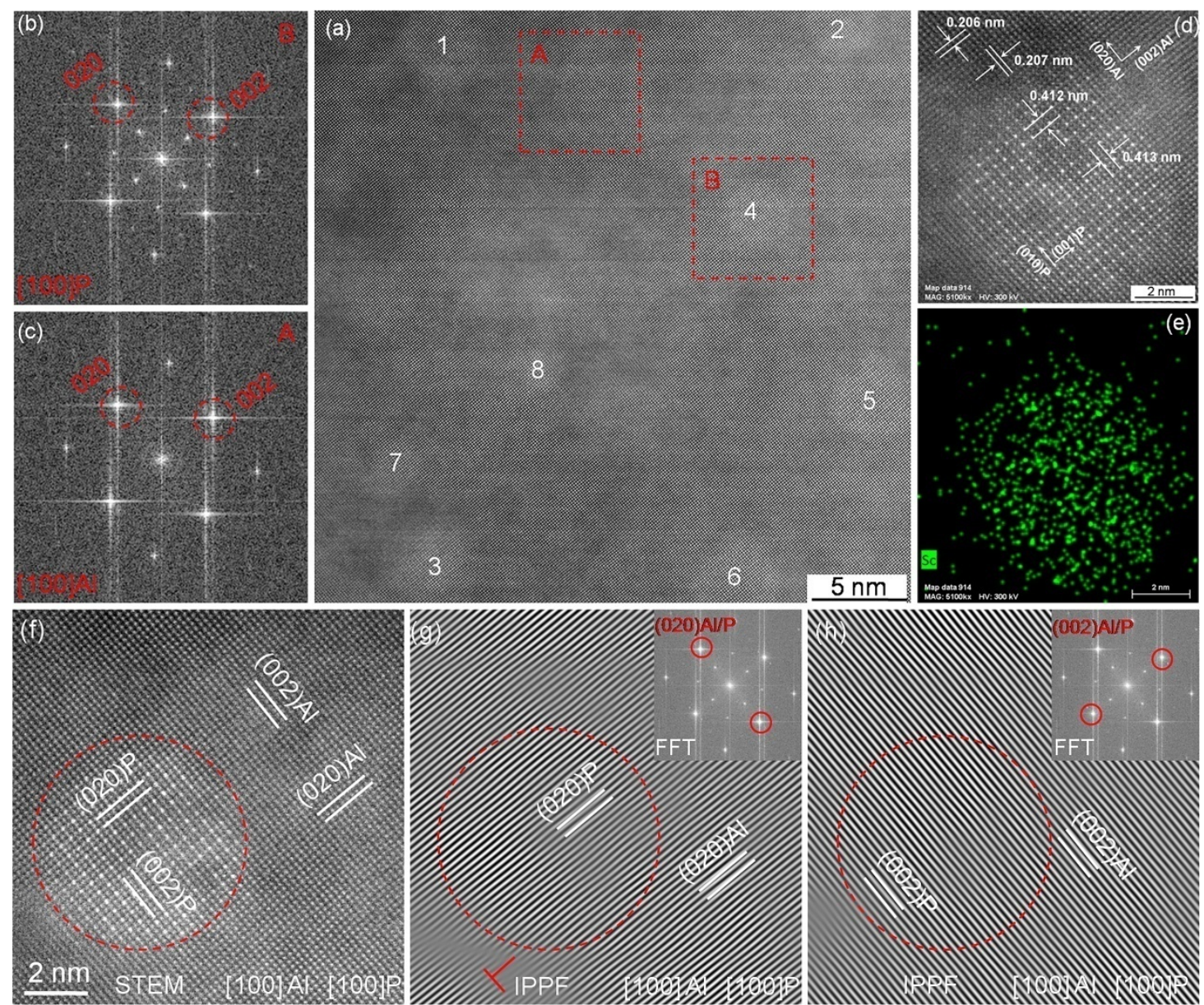

$5 \mathrm{~nm}$

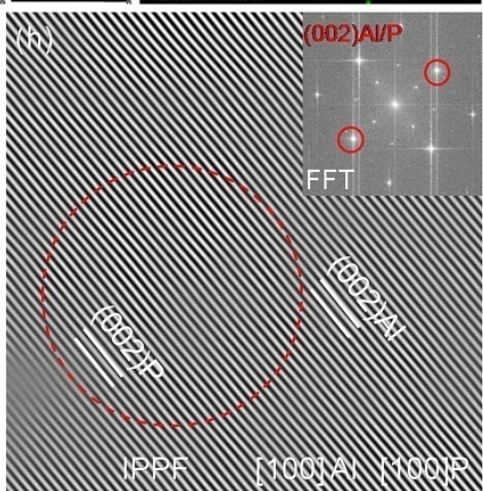

Fig. 2 STEM images of the $\mathrm{Al}_{3}(\mathrm{Sc}, \mathrm{Zr})$ precipitate obtained from the Alloy-S sample. (a) Low magnification STEM image, where 1-8 indicate the eight precipitates. (b) and (c) FFT images of precipitate 4 (red box B) and aluminium matrix (red box A). (d) Large magnification STEM image of precipitate 4 with interplanar spacing of aluminium matrix and precipitate. (e) Energy dispersive spectrometer mapping of Sc element of $(\mathrm{d})$; the $\mathrm{Zr}$ element is not shown here. $(\mathrm{f}-\mathrm{h})$ Precipitates and their corresponding IFFT images. No dislocation is observed at the $\mathrm{Al} / \mathrm{Al}_{3}(\mathrm{Sc}, \mathrm{Zr})$ interface, indicating a fully coherent interface. The red circles in ( $\mathrm{f}-\mathrm{h})$ refer to the $\mathrm{Al} / \mathrm{Al}_{3}(\mathrm{Sc}, \mathrm{Zr})$ interface. The zone axis is [001] for aluminium matrix ([001]Al) and precipitates ([001]P). The (002)Al, (020)Al, (001)P, (010)P refer to the crystallographic planes (200), (020) of aluminium matrix and (001), (010) of precipitates. The orientation relation between precipitates and matrix is [001]Al // [001]P, (002)Al // (002)P, (020)Al // (020)P. 


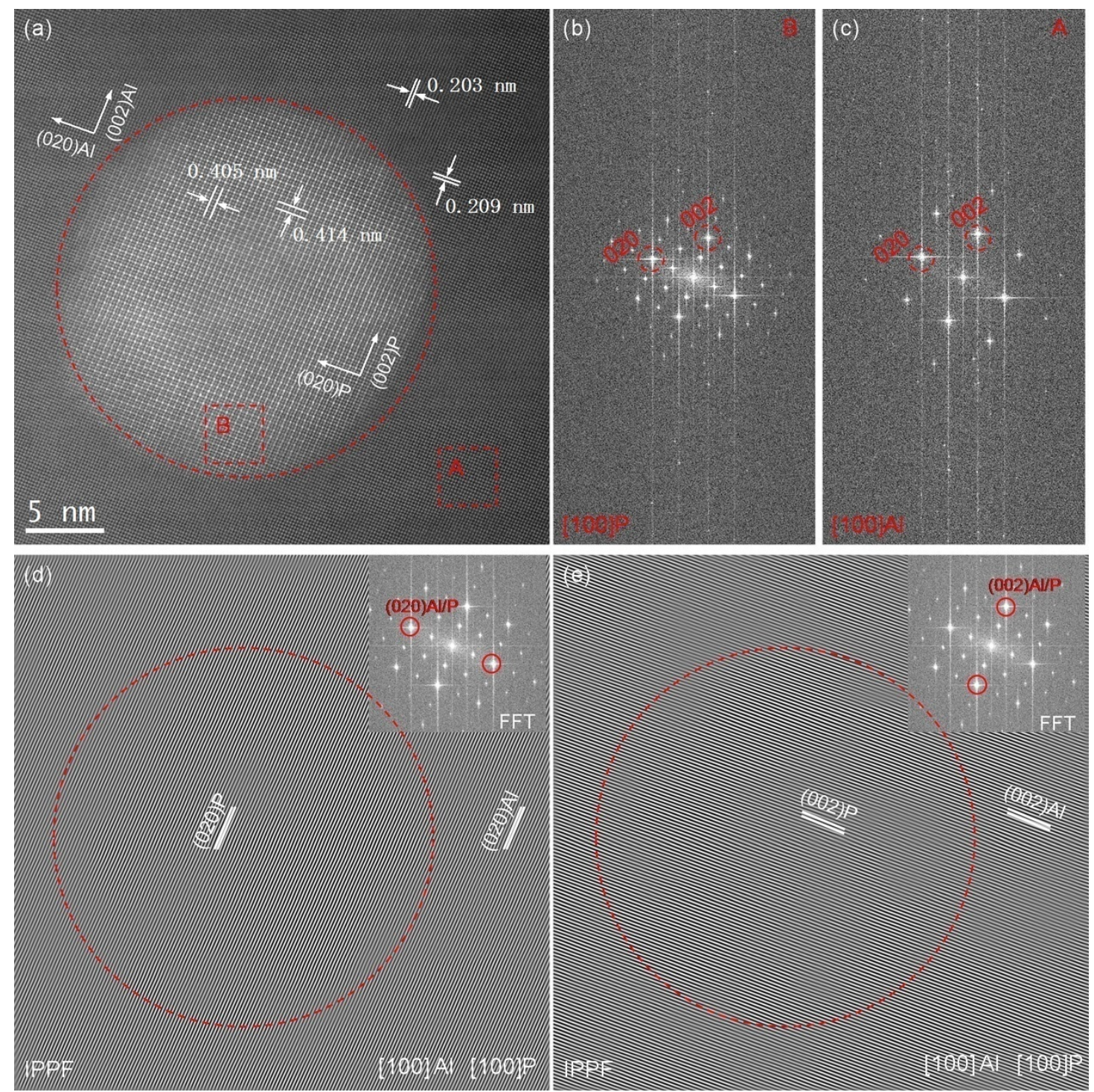

Fig. 3 STEM images of $\mathrm{Al}_{3}(\mathrm{Sc}, \mathrm{Zr})$ precipitate obtained from Alloy-NS sample: (a) STEM image; (b) and (c) FFT images of precipitate (red box B) and aluminium matrix (red box A); (d-e) the corresponding IFFT images. No dislocation is observed at $\mathrm{Al} / \mathrm{Al}_{3}(\mathrm{Sc}, \mathrm{Zr})$ interface, indicating a fully coherent interface. The red circles in (d-e) refer to the $\mathrm{Al} / \mathrm{Al}_{3}(\mathrm{Sc}, \mathrm{Zr})$ interface. The zone axis is [001] for aluminium matrix ([001]Al) and precipitates ([001]P). The (002)Al, (020)Al, (001)P, (010)P refer to the crystallographic planes (200), (020) of aluminium matrix and (001), (010) of precipitates. The orientation relation between precipitates and matrix is [001] $\mathrm{Al} / /$ [001]P, (002)Al //(002)P, (020)Al //(020)P.

Although TEM is used to observe the distribution and morphology of precipitates and analyse the interface structure of the precipitate and matrix, obtaining statistical information on precipitates effectively (e.g., average radius size, volume fraction, and inter-distance of precipitates) is difficult, particularly when the average radius size of 
precipitates is very small. In the present study, we use the SANS technique to characterise $\mathrm{Al}_{3}(\mathrm{Sc}, \mathrm{Zr})$ precipitates to obtain more realistic statistical information on the average radius size and volume fraction of Alloy-S and Alloy-NS samples, since average radius size and volume fraction are the key parameters used for modelling. Fig. 4 shows the experimental curves of scattering intensity $I$ versus scattering vector $q$ (Fig. 4(a)) as well as the corresponding two-dimensional scattering image (Figs. 4(b) and $4(\mathrm{c}))$. The $I-q$ curves are obtained after the two-dimensional scattering image is integrated azimuthally. The initial data processing on SANS experimental data contains correction, normalisation, and calibration, which are conducted by using the method proposed by Cotton [Lindner and Zemb, 1991]. According to previous studies [Mathon et al; 1997, 2003, 2012; Zhong et al., 2014], SANS intensity $I(q)$ can be expressed as $(d \Sigma / d \Omega)(q)=I(q) \approx f_{\mathrm{p}} \Delta \rho^{2} F^{2}(q, R) S(q, R)$

where $d \Sigma$ is the number of neutrons scattered per second into $d \Omega$ in each under a certain volume fraction and $d \Omega$ is the differential solid angle, $d \Sigma / d \Omega$ represents the unit scattering density across the sample; $f_{\mathrm{p}}$ refers to the precipitate atomic volume; $q$ represents the scattering vector; $S(q, R)$ refers to the interference term associated with precipitates that can be neglected when the volume fraction of the precipitate is less than a few percentage [Ashcroft and Lekner, 1966; Mathon et al., 2012; Zhong et al., 2014] $]^{1}$. Thus, it can be assumed that $S(q, R)=1$ in this study (as previous studies show that the volume fraction of $\mathrm{Al}_{3}(\mathrm{Sc}, \mathrm{Zr})$ precipitates in AlScZr-based alloy systems is usually less than one percentage) [Knipling et al., 2010; Vo et al., 2014; Taendl et al., 2016; Luca et al., 2019]. In equation (1), $F(q, R)$ is the form factor of the precipitates. For a spherical precipitate, $F(q, R)$ can be expressed as follows [Glatter and kratky, 1982]:

\footnotetext{
1 If the volume fraction of the precipitate is less than a few percentage (or the volume fraction of precipitate is very low), it indicates that this is a sparse system. In this sparse system, the interspacing between precipitates is very large, so they don't interfere with each other.
} 


$$
\begin{aligned}
F(q, R) & =\frac{1}{V} \int e^{i q r} d r=\frac{1}{4 \pi R^{3} / 3} \int e^{i q r \cos \theta} r^{2} \sin \theta d \theta d \phi d r \\
& =3\left\{[\sin (q R)-q R \cos (q R)] /(q R)^{3}\right\}
\end{aligned} .
$$

where $V$ is the volume of a precipitate; $\theta$ and $\phi$ are the variables under the spherical coordinates to simplify the double integrals. In equation (1), $\Delta \rho$ is the nuclear contrast, which can be written as

$\Delta \rho=\rho^{p}-\rho^{m}=b^{p} / v_{\mathrm{at}}^{p}-b^{m} / v_{\mathrm{at}}^{m}$

where $\rho^{m}$ and $\rho^{p}$ are the scattering length density of the matrix and precipitates, respectively; $v_{\mathrm{at}}^{m}$ and $v_{\mathrm{at}}^{p}$ are the mean atomic volumes of the matrix and precipitates, respectively; and $b^{m}$ and $b^{p}$ are the mean scattering lengths of the matrix and precipitates, respectively. As the matrix is mainly composed of the chemical elements of aluminium and magnesium, $b^{m}$ can be written as [Sears, 1992] $b^{m}=\Sigma b_{i} C i=b_{\mathrm{Al}} C_{\mathrm{Al}}+b_{\mathrm{Mg}} C_{\mathrm{Mg}}$

where $b_{\mathrm{Al}}$ and $b_{\mathrm{Mg}}$ are the nuclear scattering lengths of $\mathrm{Al}$ and $\mathrm{Mg}$ elements and $C_{\mathrm{Al}}$ and $C_{\mathrm{Mg}}$ are the mole fractions of $\mathrm{Al}$ and $\mathrm{Mg}$ elements, respectively. Based on previous studies, one Gaussian distribution is usually used to model the size distribution of precipitates, which agrees with experimental TEM observations [Zhong et al., 2014]. The distribution function $h(R)$ of one Gaussian distribution is expressed by

$$
h(R)=\exp \left[-\left(R-R_{\mathrm{m}}\right)^{2} / 2 \sigma^{2}\right] / \sqrt{2 \pi} \sigma
$$

where $R_{\mathrm{m}}$ is the mean radius of the precipitates and $\sigma$ is the standard deviation. The average inter-distance of precipitates $L_{p}$ can be expressed as [Knipling et al., 2010]

$L_{p}=R_{m} \sqrt{\left(2 \pi / 3 f_{v}\right)-\pi / 2}$.

In equation (1), the factor $f_{\mathrm{p}} \Delta \rho^{2}$ is independent of the precipitate radius, which can be considered as a fitting constant parameter. By using the small angle scattering fitting software VSAS developed by Zhong et al. of Shanghai Jiao Tong University [Zhong et al., 2014], the $R_{\mathrm{m}}, \sigma, f_{\mathrm{p}}$ and $L_{p}$ can be determined. Table 1 shows the 
values of the parameters used in fitting $R_{\mathrm{m}}, \sigma$ and $f_{\mathrm{p}}$.

Table 1 Values of parameters used in fitting $R_{\mathrm{m}}, \sigma$ and $f_{\mathrm{p}}$

\begin{tabular}{|c|c|c|c|}
\hline Parameter & Significance & Value & Origin \\
\hline$S(q, R)$ & Interference term associated with precipitates & 1 & [Zhong et al., 2014] \\
\hline$\rho^{m}$ & Scattering length density of matrix & $2.16 \times 10^{10} \mathrm{~cm}^{-2}$ & Equation (3) \\
\hline$\rho^{p}$ & Scattering length density of precipitate & $3.36 \times 10^{10} \mathrm{~cm}^{-2}$ & Equation (3) \\
\hline$v_{\mathrm{at}}^{m}$ & Mean atomic volume of matrix & $1.65 \times 10^{-23} \mathrm{~cm}^{-2}$ & - \\
\hline$v_{\mathrm{at}}^{p}$ & Mean atomic volume of precipitate & $1.69 \times 10^{-23} \mathrm{~cm}^{-2}$ & - \\
\hline$b^{m}$ & Mean scattering length of matrix & $3.563 \times 10^{-13} \mathrm{~cm}$ & Equation (4) \\
\hline$b^{p}$ & Mean scattering length of precipitate & $22.637 \times 10^{-13} \mathrm{~cm}$ & [Sears, 1992] \\
\hline$C_{\mathrm{Al}}$ & Mole fraction of $\mathrm{Al}$ & $94.1 \%$ & - \\
\hline$C_{\mathrm{Mg}}$ & Mole fraction of $\mathrm{Mg}$ & $5.9 \%$ & - \\
\hline$b_{\mathrm{Al}}$ & Nuclear scattering lengths of $\mathrm{Al}$ element & $3.449 \times 10^{-13} \mathrm{~cm}$ & [Sears, 1992] \\
\hline$b_{\mathrm{Mg}}$ & Nuclear scattering lengths of $\mathrm{Mg}$ element & $5.375 \times 10^{-13} \mathrm{~cm}$ & [Sears, 1992] \\
\hline
\end{tabular}



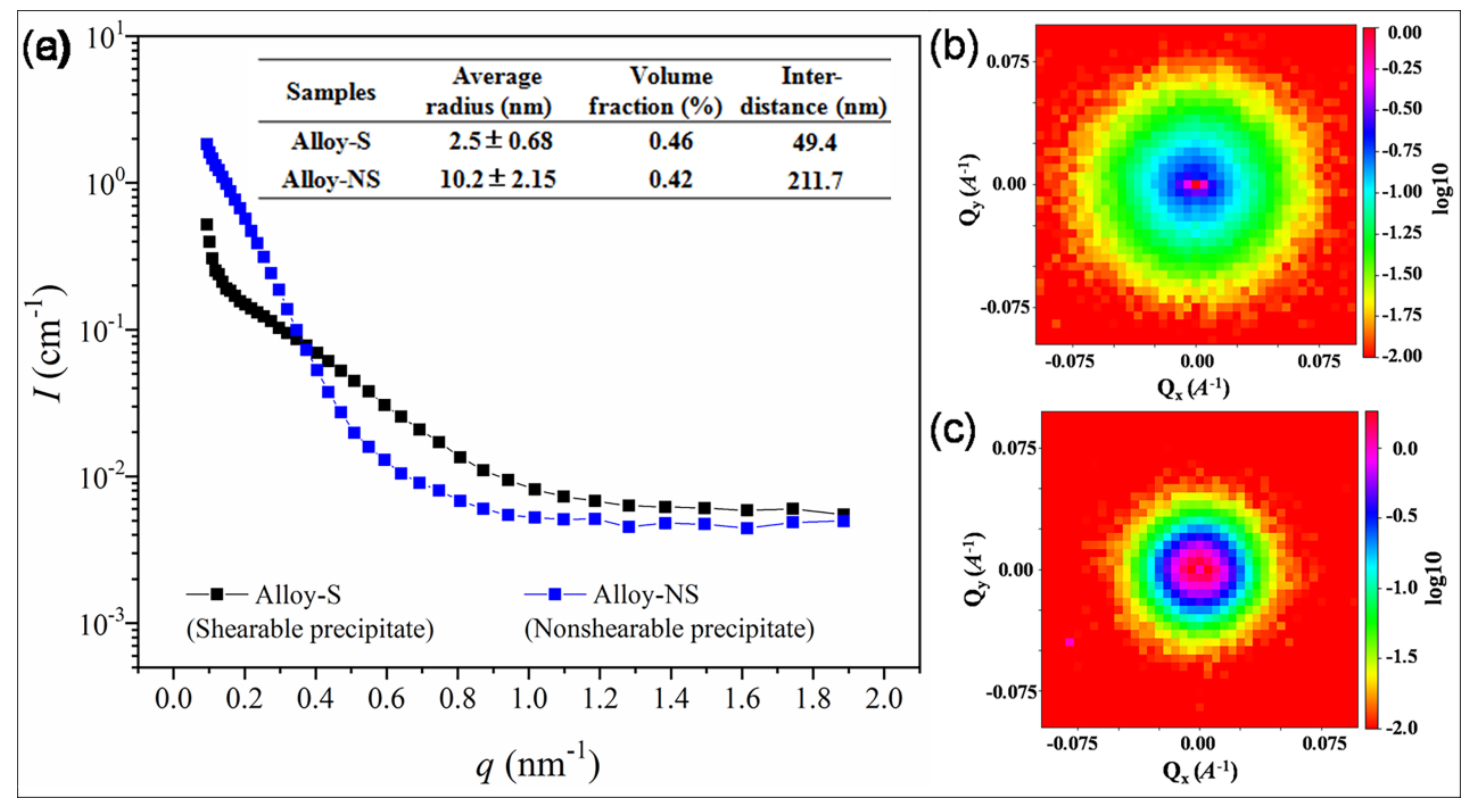

Fig. 4 Quantitative characterisation of $\mathrm{Al}_{3}(\mathrm{Sc}, \mathrm{Zr})$ precipitates by SANS. (a) Scattering intensity $I$ versus scattering vector $q$ for Alloy-S and Alloy-NS samples obtained by SANS. The inserted table presents the mean radius, volume fraction, and inter-distance of the precipitates for both samples obtained by SANS. (b) and (c) are the two-dimensional scattering images of Alloy-S and Alloy-NS samples.

Fig. 4 shows the quantitative information of $\mathrm{Al}_{3}(\mathrm{Sc}, \mathrm{Zr})$ precipitates of the Alloy-S and Alloy-NS samples. The average sizes of precipitates formed are approximately 2.5 and $10.2 \mathrm{~nm}$ in the Alloy-S and Alloy-NS samples. The volume fractions of the precipitates in these alloys are determined to be approximately $0.46 \%$ and $0.42 \%$, respectively. These results are very similar to those reported for Al-Sc-Zr alloys [Iwamura and Miura, 2004; Robson, 2004; Marquis and Seidman, 2005; Clouet et al., 2005; Fuller and Seidman, 2005; Knipling et al., 2010].

In summary, the quantitative information of precipitates containing the average size, volume fraction and inter-distance is obtained by TEM and SANS. This information is necessary for clarifying the influence of different dislocation-precipitate interactions on the dislocation behaviour during deformation (such as the distribution of dislocations and magnitude of dislocation density). It can also further provide the key parameters for our modified dislocation-based approach. These results support the explanation regarding the underlying dislocation mechanism of ductility during precipitation which will be discussed in the following sections. 


\subsection{Analysis of variation of ductility during precipitation}

Figs. $5(\mathrm{a}-\mathrm{g})$ show the engineering stress-strain curves of AlMg, Alloy-S, and Alloy-NS alloys at different strain rates $0.05-0.00005 \mathrm{~s}^{-1}$. The Portevin-Le Chatelier phenomenon (PLC) is observed from engineering stress-strain curves that results from the interaction between solute atoms and mobile dislocations [Cottrell and Bilby, 1949; McCormick, 1972; Van den Beukel, 1975; Estrin and Kubin, 1990; Kubin and Estrin, 1985, 1990, 1991; Antolovich and Armstrong, 2014; Zhang et al., 2017] ${ }^{2}$. We do not intend to focus on the PLC phenomenon; therefore, it is not described in detail in this paper. Fig. 5 (h) shows the strain rate sensitivity (m) of the AlMg, Alloy-S, and Alloy-NS alloys. The strain rate sensitivity is controlled by the thermally activated interactions of dislocations with obstacles that can be computed using the equation $m=\log \left(\sigma_{1} / \sigma_{2}\right) / \log \left(\dot{\varepsilon}_{1} / \dot{\varepsilon}_{2}\right)$, where $\sigma_{1}$ and $\sigma_{2}$ refer to the flow stress at a constant strain rate of $\dot{\varepsilon}_{1}$ and $\dot{\varepsilon}_{2}$ respectively [Wang et al., 2006; Zhao et al., 2018]. As can be observed in the figure, the m values of AlMg, Alloy-S, and Alloy-NS alloys are $-0.0091,-0.0073$, and -0.0130 , respectively. The three values are very close, indicating that the precipitation does not lead to a significant change on $\mathrm{m}$ value.

The AlMg alloy with conspicuous necking growth strain (the strain from appearance of necking to final fracture) is presented in Figs. 5 (a-g). For Alloy-S alloy (with shearable precipitates), the plastic instability point is advanced; this indicates that the ductility decreases with the formation of shearable precipitates. When the shearable precipitates become nonshearable precipitates, the ductility is increased again. The variations in ductility during precipitation are shown in Fig. 8.

\footnotetext{
2 For AlMg alloy, the mobile dislocations can be impeded and arrested by forest dislocations during deformation. The solute Mg atoms will diffuse to the arrested mobile dislocations and pin these arrested mobile dislocations during this waiting time. The additional pinning caused by solute atoms will lead to a stress rise in the stress-strain curve. With the increase of applied stress, the arrested mobile dislocations will escape from the additional pinning of solute atoms, leading to a stress drop or stress plateau.
} 

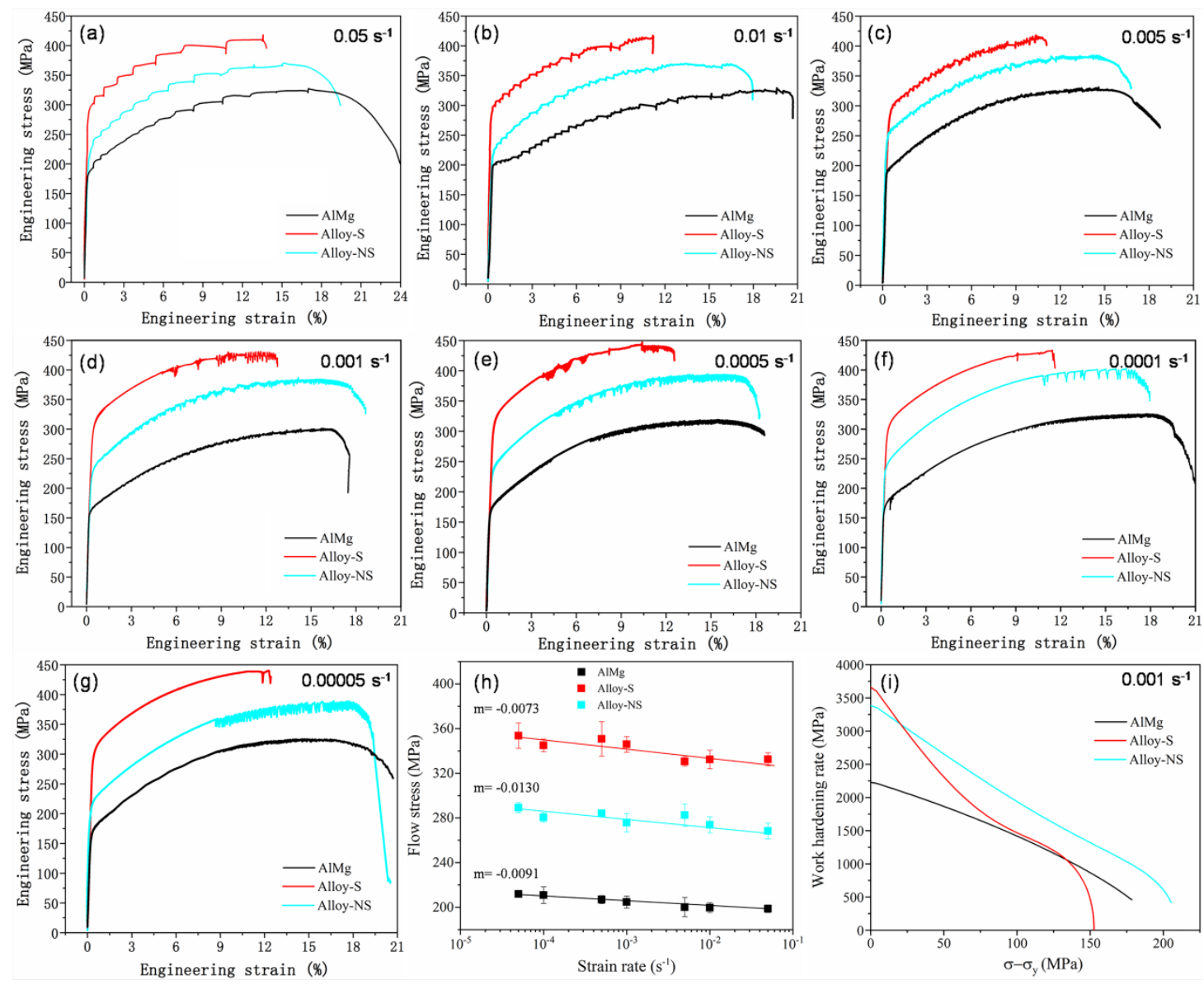

Fig. 5 (a-g) Engineering stress strain curves of AlMg, Alloy-S, and Alloy-NS samples at different strain rates: (a) $0.05 \mathrm{~s}^{-1}$, (b) $0.01 \mathrm{~s}^{-1}$, (c) $0.005 \mathrm{~s}^{-1}$, (d) $0.001 \mathrm{~s}^{-1}$, (e) 0.0005 $\mathrm{s}^{-1}$, (f) $0.0001 \mathrm{~s}^{-1}$, and (f) $0.00005 \mathrm{~s}^{-1}$. (h) Variations of flow stress versus strain rate at constant strain $(2 \%)$ for AlMg, Alloy-S, and Alloy-NS samples; the strain rate sensitivity (m) is determined. (i) Work hardening rate versus the flow stress with the yield stress subtracted at $0.001 \mathrm{~s}^{-1}$ for AlMg, Alloy-S, and Alloy-NS samples.

The dislocation-precipitate interactions include dislocation shearing precipitates (hereinafter referred to as shearable precipitates) and dislocation bypassing precipitates (hereinafter referred to as nonshearable precipitates) [Ardell, 1985; Gladman, 1999; Hull and Bacon, 2011; Ma et al., 2014; Fan et al., 2018; Xu et al., 2019; Li et al., 2020]. For many alloy systems, the shearing mechanism changes into bypassing mechanism with an increase in the precipitate size. For the AlScZr alloy system, it has been reported that the critical size between shearable precipitates and nonshearable precipitates is previously found to be approximately $3 \sim 4 \mathrm{~nm}$ [van Dalen et al., 2006; Fazeli et al., 2008; Knipling et al., 2010, 2011; Lai et al., 2013; Luca et al., 2018; Okle et al., 2019]. Therefore, the precipitates in Alloy-S (with an average 
precipitate size of approximately $2.5 \mathrm{~nm}$ ) and Alloy-NS (with an average precipitate size of approximately $10.2 \mathrm{~nm}$ ) samples are understood to be shearable and nonshearable precipitates, respectively. Fig. 6 shows the dark-field TEM images of $\mathrm{Al}_{3}(\mathrm{Sc}, \mathrm{Zr}$ ) precipitates taken from Alloy-S and Alloy-NS samples after 5\% tensile strains. It can be seen that the precipitates are sheared by dislocations for Alloy-S samples, while no evident dislocation shearing precipitates is observed for Alloy-NS sample. Our results are similar to the previous studies of Xiao et al. and Jaladurgam et al. who also reported the dislocations shearing precipitates from TEM observation [Xiao et al., 2005; Jaladurgam et al., 2020]. From Fig. 6, it also can be seen that the precipitates in Alloy-S and Alloy-NS samples are shearable and nonshearable precipitates.
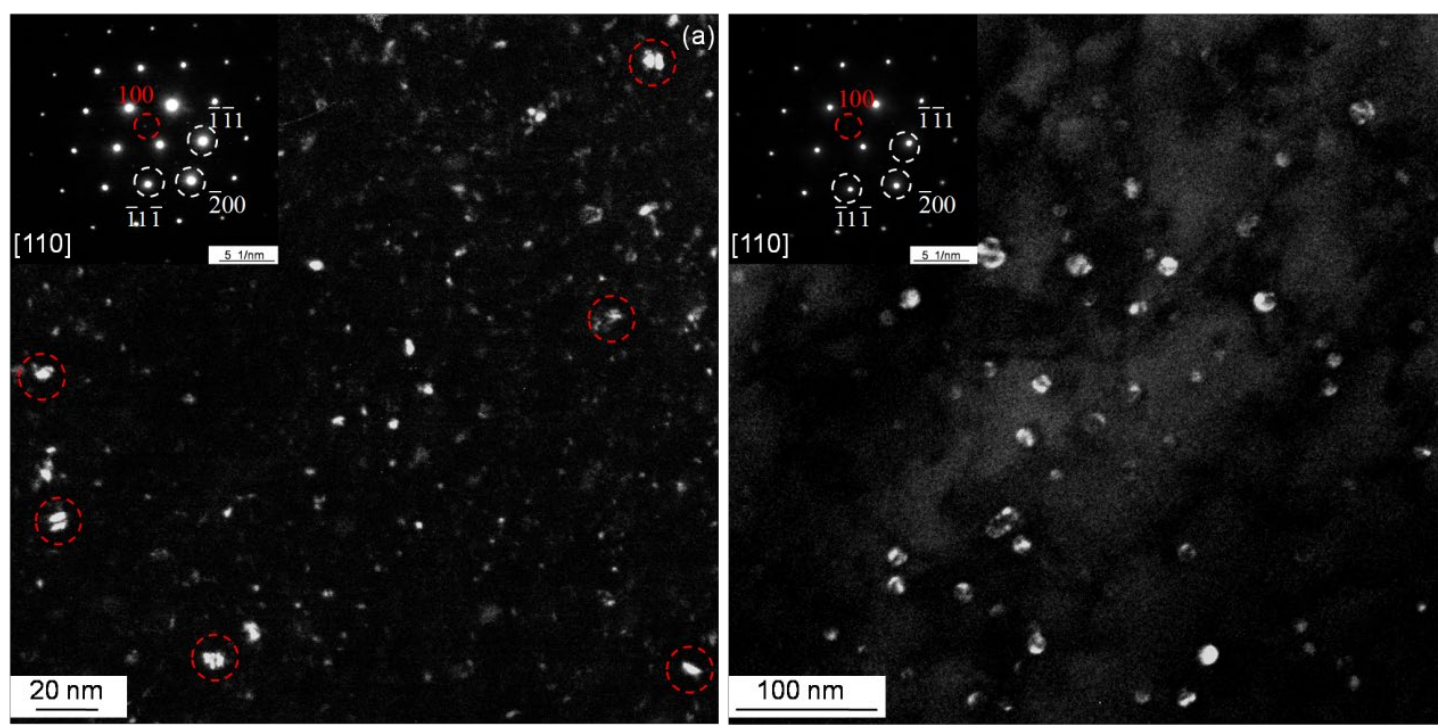

Fig. 6 Dark-field TEM images of $\mathrm{Al}_{3}(\mathrm{Sc}, \mathrm{Zr})$ precipitates taken from extruded Alloy-S and Alloy-NS samples after 5\% tensile strains: (a) Alloy-S (made with the 100 diffraction spot), (b) Alloy-NS (made with the 100 diffraction spot). The dashed red circles in (a) show that the precipitates are sheared by dislocations. The inset figures correspond to selected area electron diffraction.

To further verify that the precipitates in Alloy-S and Alloy-NS are shearable and nonshearable precipitates, we compare the precipitation strengthening increment caused by theoretical model prediction and experimental data (Fig. 7).

First of all, when the resistance force caused by hard particles is higher than the double line tension, and the dislocation will bypass the hard particles in the form of 
Orowan loop. The Orowan strengthening $\sigma_{\text {oro }}$ is given by [Knipling et al., 2010; Ma et al., 2014; Luca et al., 2019]:

$\sigma_{\text {oro }}=0.4 M G b \ln (2 \bar{R} / \mathrm{b}) / \pi L_{p} \sqrt{1-v}$.

Secondly, the order strengthening, owing to the formation of antiphase boundaries (APBs), can lead to the increase of strength when the mobile dislocations shear the ordered precipitates [Ardell et al., 1985; Knipling et al., 2010; Ma et al., 2014; Luca et al., 2019]. The order strengthening $\sigma_{\text {ord }}$ is expressed as:

$\sigma_{\text {ord }}=M \cdot\left(0.81 \eta_{A P B s} / 2 b\right) \cdot(3 \pi \phi / 8)^{1 / 2}$.

Thirdly, the coherent strengthening, which is due to the elastic strain field interactions between coherent precipitates and dislocations. The coherent strength $\sigma_{\text {coh }}$ is given by [Ardell et al., 1985; Knipling et al., 2010; Ma et al., 2014; Luca et al., 2019]:

$\sigma_{\mathrm{coh}}=M \cdot \chi(\xi G)^{3 / 2} \cdot(R \phi b / T)^{1 / 2}$.

Fourthly, the modulus strengthening, owing to the modulus misfit, results from the shear modulus difference between matrix and precipitate. The modulus strengthening $\sigma_{\bmod }$ is shown as [Ardell et al., 1985; Knipling et al., 2010; Ma et al., 2014; Luca et al., 2019]:

$\sigma_{\text {mod }}=M \cdot 0.0055(\Delta G)^{3 / 2}(\phi / T)^{1 / 2} \cdot b(R / b)^{3 m / 2-1}$.

The former studies in [van Dalen et al., 2006; Knipling et al., 2010; Vo et al., 2012; Lefebvre et al., 2014] indicate that the combined modulus-coherent strengthening dominates when $R<R_{1}$. When $R_{1} \leq R \leq R_{2}$, the order strengthening dominates. When $R>R_{2}$, the Orowan strengthening dominates. Therefore, one obtains:

$\sigma=\left\{\begin{array}{l}\sqrt{\sigma_{\text {mod }}^{2}+\sigma_{\text {coh }}^{2}}, R<R_{1} \\ \sigma_{\text {ord }}, R_{1} \leq R \leq R_{2} \\ \sigma_{\text {oro }}, R>R_{2}\end{array}\right.$.

For $\mathrm{Al}_{3}(\mathrm{Sc}, \mathrm{Zr})$ precipitate, $R_{1} \approx 1.2 \mathrm{~nm}$ and $R_{2} \approx 3-4 \mathrm{~nm}$ [van Dalen et al., 2006;

Fazeli et al., 2008; Knipling et al., 2010, 2011; Lai et al., 2013; Luca et al., 2019;

Okle et al., 2019]. 
Table 2 The parameters in equations $(7-10)$

\begin{tabular}{|c|c|c|c|}
\hline Parameter & Significance & Value & Origin \\
\hline$R$ & Average size of precipitates & $2.5 / 10.2 \mathrm{~nm}$ & This study \\
\hline$\phi$ & Volume fractions of precipitates & $0.46 \% / 0.42 \%$ & This study \\
\hline$M$ & Taylor mean orientation factor & 3.06 & [Knipling et al., 2010] \\
\hline$G$ & Shear modulus of aluminum & $26.2 \mathrm{GPa}$ & [Knipling et al., 2010] \\
\hline $\mathrm{b}$ & Burgers vector & $0.286 \mathrm{~nm}$ & [Knipling et al., 2010] \\
\hline$L_{p}$ & Average inter-distance of precipitates & $49.4 / 211.7 \mathrm{~nm}$ & This study \\
\hline $\bar{R}$ & Average planar radius & $\bar{R}=0.25 R$ & [Knipling et al., 2010] \\
\hline$v$ & Poisson's ratio of aluminum & 0.345 & [Knipling et al., 2010] \\
\hline$\eta_{A P B S}$ & $\begin{array}{l}\text { Average value of the APBs energy for } \\
\text { (111) plane }\end{array}$ & $0.5 \mathrm{~J} \mathrm{~m}^{-2}$ & [Knipling et al., 2010] \\
\hline$\chi$ & A constant & 2.6 & [Knipling et al., 2010] \\
\hline$T$ & Line tension of the dislocation & $1.072 \times 10^{-9} \mathrm{~N}$ & [Knipling et al., 2010] \\
\hline$\xi$ & $\begin{array}{l}\text { A misfit parameter describing the misfit } \\
\text { degree between precipitate and dislocation }\end{array}$ & 0.0179 & [Knipling et al., 2010] \\
\hline$\Delta G$ & $\begin{array}{l}\text { Absolute value of shear modulus } \\
\text { difference between matrix and precipitate }\end{array}$ & $41.8 \mathrm{GPa}$ & [Knipling et al., 2010] \\
\hline$m$ & A constant & 0.85 & [Knipling et al., 2010] \\
\hline
\end{tabular}

For the Alloy-S sample, the predicted values by combined modulus-coherent strengthening, order strengthening and Orowan strengthening are about 210, 160, 190 $\mathrm{MPa}$ when average size of precipitate is about $2.5 \mathrm{~nm}$. The experimental value is about $140 \mathrm{MPa}$, which is close to the predicted value by order strengthening (the experimental result is lower than that of the predicted strengthening increment, possibly owing to some variation in the reported values of APBs energy of the $\mathrm{Al}_{3}(\mathrm{Sc}$, Zr) precipitate [Knipling et al., 2010; Lefebvre et al., 2014]). Thus, it is inferred that the order strengthening is the dominant strengthening for Alloy-S sample. For the Alloy-NS sample, the predicted values by combined modulus-coherent strengthening, order strengthening and Orowan strengthening are about 350, 152, $69 \mathrm{MPa}$ when average size of precipitate is about $10.2 \mathrm{~nm}$. The experimental value is about $70 \mathrm{MPa}$, which is very close to the predicted value by Orowan strengthening. Thus, it is 
inferred that the Orowan strengthening is the dominant strengthening for Alloy-NS sample. Through comparison between experimental measurements and strengthening model predictions, the precipitates in the Alloy-S and Alloy-NS samples can be verified to be shearable and nonshearable, respectively.
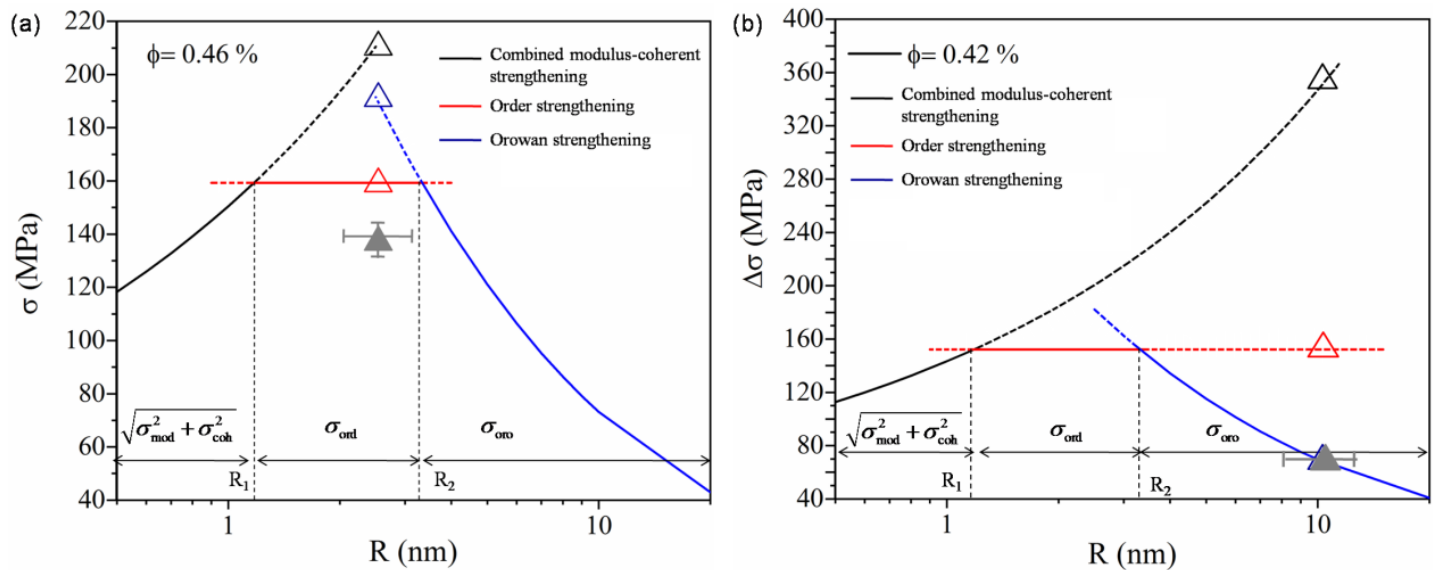

Fig. 7 Yield stress increment versus mean precipitate radius for (a) Alloy-S and (b) Alloy-NS. The full curves represent calculated predictions of minimum of $\sqrt{\sigma_{\text {mod }}^{2}+\sigma_{\text {coh }}^{2}}, \sigma_{\text {ord }}$, and $\sigma_{\text {oro }}$. That is, the minimum value of $\sqrt{\sigma_{\text {mod }}^{2}+\sigma_{\text {coh }}^{2}}, \sigma_{\text {ord }}$, and $\sigma_{\text {oro }}$ is the true strengthening increment. $R_{1}$ (inflection point) is the critical radius between combined modulus-coherent strengthening and order strengthening. $R_{2}$ (inflection point) is the critical radius between order strengthening and Orowan strengthening. The black, red and blue triangles refer to the predicted values by combined modulus-coherent strengthening, order strengthening and Orowan strengthening when the average size of precipitate is about $2.5 \mathrm{~nm}$ (a) and $10.2 \mathrm{~nm}$ (b). The grey triangles in (a) and (b) refer to the experimental results.

\section{Theoretical modelling}

\subsection{Modified dislocation-based approach}

Up to now, many theoretical models have been developed to describe the strengthening during precipitation, such as the models in equations (7-10). However, the existing theoretical models are difficult to describe the variation of ductility during precipitation. Although the Considère criterion $(\theta(\varepsilon) / \sigma(\varepsilon)=1)$ and Hart criterion 
$(\theta(\varepsilon) / \sigma(\varepsilon)+m=1$, where $m$ is the strain rate sensitivity) can be used to predict the necking instability points [Considère, 1885; Hart, 1967], both two criteria do not follow any specific strain-hardening law. The necking instability point is difficult to estimate accurately unless the function $\sigma(\varepsilon)$ in the entire strain range can be determined. However, the most used constitutive equations, such as Hollomon $\left(\sigma(\varepsilon)=K \varepsilon^{n}\right)$, Ludwik-Hollomon $\left(\sigma(\varepsilon)=K \dot{\varepsilon}^{m} \varepsilon^{n}\right)$, and Swift $\left(\sigma(\varepsilon)=K\left(\varepsilon_{0}+\varepsilon\right)^{n}\right)$, are empirical. These constitutive equations sometimes make it difficult to describe the actual strain-hardening behaviour of materials. Therefore, the estimated necking strain by the Considère (or Hart) criterion is different from the actual value. For example, the Considère criterion indicates that the necking strain and strain exponent are identical in the Hollomon relation for strain rate insensitive materials: $\varepsilon_{N C}=n$. However, for strain rate sensitivity materials, the necking strain is determined as $\varepsilon_{N H}=n /(1-m)$ in Ludwik-Hollomon expression using the Hart criterion. Table 3 lists the necking strains obtained using the Considère criterion $\left(\varepsilon_{N C}\right)$ and Hart criterion $\left(\varepsilon_{N H}\right)$. It can be seen that $\varepsilon_{N C}$ is almost equal to $\varepsilon_{N H}$, which is much higher than that of the real necking strain determined experimentally $\varepsilon_{N}$. Therefore, predicting the necking instability points and discussing the dislocation mechanism of ductility variation in metals during precipitation are difficult using these empirical constitutive equations and the Considère (or Hart) criterion.

Table 3 Necking strains (uniform elongation) determined by Considère and Hart criteria-based prediction and experimental characterisation

\begin{tabular}{cccc}
\hline Samples & AlMg & Alloy-S & Alloy-NS \\
\hline$n$ & 0.252 & 0.167 & 0.220 \\
$\varepsilon_{N C}$ & 0.252 & 0.167 & 0.220 \\
$\varepsilon_{N H}$ & 0.249 & 0.166 & 0.218 \\
$\varepsilon_{N}$ & 15.833 & 11.148 & 14.867 \\
\hline
\end{tabular}

The tensile tests are conducted in $0.05-0.00005 \mathrm{~s}^{-1}$ range. The values in this table refer to the 
average value from all tensile tests.

In this study, we propose a dislocation-based approach to quantitatively demonstrate and predict the ductility variation during precipitation for precipitation hardening AlMgScZr alloys. This dislocation-based approach was first proposed by Yasnikov et al. who used to predict the variation of plastic instability in metals without precipitates [Yasnikov et al., 2014, 2017; Vinogradov et al., 2016]. In the present study, we propose a modified dislocation-based approach to study the variation in ductility during precipitation for AlMgScZr alloy. Moreover, we clarify the physical mechanisms behind this modified dislocation-based approach combined with experimental verification. This modified dislocation-based approach couples the Taylor constitutive equation, which describes the relationship between flow stress and total dislocation density, and a kinetic equation describing the relationship between the dislocation density and plastic strain or deformation time.

For the AlMg alloy, the equation suggested by Kocks, Mecking, and Estrin that govern the evolution of the total density is expressed as follows [Kocks, 1976; Estrin and Mecking, 1984; Estrin, 1996]:

$d \rho / d t=\left(k_{1} \sqrt{\rho}-k_{2} \rho\right) \dot{\gamma}^{p}$,

where $k_{1}$ is a constant representing the dislocation storage due to trapping of the dislocations by other dislocations; $k_{2}$ depends on the strain rate and temperature that represents a reduction in dislocation caused by dynamic recovery, and $\dot{\gamma}^{p}$ is the shear strain rate. Variational methods (assuming $\delta \rho$ and $\delta \dot{\gamma}^{p}$ are small fluctuations of $\rho$ and $\dot{\gamma}^{p}$ ) and linear stability analysis are used to define the plastic instability criterion. Finally, we obtain the instability criterion for single-phase coarse-grained material based on the dislocation evolution, as shown in [Vinogradov et al., 2016; Yasnikov et al., 2017]

$\left(\theta^{N} / \sigma\right)(1-m)+\left(m / \varepsilon^{N}\right)\left(1-\left(\sigma_{0} / \sigma\right)\right)=1$ 
where $\sigma_{0}$ represents the stress for resisting dislocation slip that usually originates from solutes, Peierls stress, and initial dislocation density, prior to plastic deformation; $\theta^{N}=\left(\sigma_{S}^{N} / \varepsilon^{N}\right) \cdot \exp \left(-\varepsilon / \varepsilon^{N}\right)$ and the characteristic strain $\varepsilon^{N}=2 / M k_{2}$ (where $M$ is Taylor factor); and the saturated stress $\sigma_{S}^{N}=a G b M k_{1} / k_{2}$ (where $\alpha$ is a constant, $G$ is the shear modulus, and $b$ is the Burgers vector). Therefore, the critical strain obtained from the instability criterion is expressed as follows

$$
\varepsilon_{c}^{N}=\varepsilon^{N} \ln \left[\left(1+(1-2 m) / \varepsilon^{N}\right) /\left(1+\left(\sigma_{0} / \sigma_{S}^{N}\right)-\left(m / \varepsilon^{N}\right)\right)\right] .
$$

For the Alloy-S with shearable precipitates, considering the effect of shearable precipitates, the evolution of the total dislocation density with increasing strain or time becomes

$d \rho / d t=\left(k_{1} \sqrt{\rho}-f_{s} k_{2} \rho\right) \dot{\gamma}^{p}$,

where $f_{s}$ is a term representing the effect of shearable precipitates on dynamic recovery [Cheng et al., 2003]. Thus, the instability criterion and critical strain for necking can be expressed by equations (16) and (17) as follows

$\left(\theta^{S} / \sigma\right)(1-m)+\left(m / \varepsilon^{S}\right)\left(1-\left(\sigma_{0} / \sigma\right)\right)<1$,

$\varepsilon_{c}^{S}=\varepsilon^{S} \ln \left[\left(1+(1-2 m) / \varepsilon^{S}\right) /\left(1+\left(\sigma_{0} / \sigma_{S}^{S}\right)-\left(m / \varepsilon^{S}\right)\right)\right]$,

where $\theta^{S}=\left(\sigma_{S}^{S} / \varepsilon^{S}\right) \cdot \exp \left(-\varepsilon / \varepsilon^{S}\right)$, characteristic strain $\varepsilon^{S}=2 / f_{s} M k_{2}$, and saturated $\operatorname{stress} \sigma_{S}^{S}=a G b M k_{1} / f_{s} k_{2}$.

Comparatively, for the Alloy-NS containing nonshearable precipitates, we consider a case where the density of the precipitates is larger than that of the obstacles caused by dislocations for simplicity (the inter-distance between the precipitates $L_{p}$, $L_{p}<10 / \sqrt{\rho}$ [Estrin, 1996], which is confirmed by our SANS results). In this case, the evolution of total dislocation density with the increase in strain can be expressed as follows

$d \rho / d t=\left(k_{0}-f_{n s} k_{2} \rho\right) \dot{\gamma}^{p}$, 
where $k_{0}$ is a constant representing the intrinsic length scale of the material which accounts for dislocation storage. If the material contains precipitates, $k_{0}$ will depend on the spacing of the precipitates [Cheng et al., 2003]. Further, $f_{n s}$ represents the influence of nonshearable precipitates on the dynamic recovery. Therefore, the instability criterion can be expressed as follows

$\left(\theta^{N S} / \sigma\right)+\left(m / \varepsilon^{N S}\right)\left(1-\left(\sigma_{0} / \sigma\right)\right)=1$,

where $\theta^{N S}=\left(\sigma_{S}^{N S} / \varepsilon^{N S}\right) \cdot \exp \left(-\varepsilon / \varepsilon^{N S}\right) ;$ the characteristic strain $\varepsilon^{N S}=1 / f_{n s} k_{2} M$ and the saturated stress $\sigma_{S}^{N S}=a G b M \sqrt{k_{0} / f_{n s} k_{2}}$. The critical necking strain can be expressed as follows

$\varepsilon_{C}^{N S}=-\varepsilon^{N S} \ln \left\{1-\left[\sqrt{\frac{1}{1+2 \varepsilon^{N S}}+\left[\frac{\sigma_{0} \varepsilon^{N S}}{\sigma_{S}^{N S}\left(1+2 \varepsilon^{N S}\right)}\right]^{2}}-\frac{\sigma_{0} \varepsilon^{N S}}{\sigma_{S}^{N S}\left(1+2 \varepsilon^{N S}\right)}\right]^{2}\right\}$.

Equations (14), (17), and (20) are the modified dislocation-based models that can be used to predict the ductility during precipitation for precipitation hardening alloys. These modified dislocation-based models consider intrinsic microscopic variables associated with dislocation evolution.

\subsection{Model verification}

A more general equation of the flow stress addition law can be represented as follows, considering solution strengthening, dislocation strengthening, and precipitation strengthening [Cheng et al., 2003; Fazeli et al., 2008]:

$\sigma_{\text {total }}=\sigma_{A l}+\sigma_{\mathrm{ss}}+\sigma_{\mathrm{gs}}+\left(\sigma^{n}+\sigma_{\mathrm{ppt}}{ }^{n}\right)^{1 / n}$.

Here, $1 \leq n \leq 2 ; \sigma_{\mathrm{Al}}$ is the initial yield stress of pure aluminium; $\sigma_{\mathrm{ss}}$ refers to the solute strengthening; $\sigma_{\mathrm{gs}}$ is the grain boundary strengthening. The average grain sizes of extruded AlMg, Alloy-S and Alloy-NS samples are about 16.0, 8.2 and 8.5 $\mu \mathrm{m} . \quad \sigma$ is the dislocation strengthening, and $\sigma_{\mathrm{ppt}}$ represents the precipitation strengthening. The well-known Voce equation can be written as follows: 
$\sigma=\sigma_{S}-\sigma_{S} \exp \left[-\left(\theta_{0} / \sigma_{S}\right) \cdot \varepsilon^{p}\right]$

After substituting equation (22) into equation (21) and then differentiating with strain, we obtain

$\theta_{\text {total }}=\left[\left(\sigma_{\mathrm{ppt}}{ }^{n}+\sigma^{n}\right)^{\frac{1-n}{n}} \sigma^{n-1}\right] \cdot \theta_{0}\left(1-\sigma / \sigma_{S}\right)$.

For AlMg, $\sigma_{\text {total }}=\sigma_{A l}+\sigma_{\mathrm{ss}}+\sigma+\sigma_{\mathrm{gs}}$, and equation (23) becomes, $\theta_{\text {total }}=\theta_{0}\left[1-\left(\sigma / \sigma_{S}^{N}\right)\right]$, where $\theta_{0}=\alpha G b k_{1} M^{2} / 2$ and $\sigma_{S}^{N}=a G b M k_{1} / k_{2}$. After differentiating with $\sigma_{\text {total }}$, we obtain

$d \theta_{\text {total }} / d \sigma_{\text {total }}=-\theta_{0} / \sigma_{S}^{N}=-M k_{2} / 2$

Thus, $k_{1}$ and $k_{2}$ can be obtained based on equations (23) and (24). This is because $k_{2}$ denotes the slope of the work-hardening rate versus the flow stress and $k_{1}$ reflects the initial work-hardening rate.

For Alloy-S, $n=1$ [Cheng et al., 2003; Fazeli et al., 2008], $\sigma_{\text {total }}=\sigma_{A l}+\sigma_{\mathrm{ss}}+\sigma_{\mathrm{gs}}+\sigma+\sigma_{\mathrm{ppt}}$, and equation (23) becomes, $\theta_{\text {total }}=\theta_{0}\left(1-\sigma / \sigma_{S}^{S}\right)$, where $\theta_{0}=\alpha G b k_{1} M^{2} / 2$ and $\sigma_{S}^{S}=a G b M k_{1} / f_{s} k_{2}$. After differentiating with $\sigma_{\text {total }}$, we obtain

$d \theta_{\text {total }} / d \sigma_{\text {total }}=-\theta_{0} / \sigma_{S}^{S}=-f_{s} M k_{2} / 2$.

Thus, $k_{1}$ and $f_{s}$ parameters (we assume that $k_{2}$ is a constant, and the effect of shearable precipitates on dynamic recovery is reflected by $f_{s}$ ) can be obtained based on equations (23) and (25).

For Alloy-NS, $n=2$ [Cheng et al., 2003; Fazeli et al., 2008], $\sigma_{\text {total }}=\sigma_{A l}+\sigma_{\mathrm{ss}}+\sigma_{\mathrm{gs}}+\left(\sigma^{2}+\sigma_{\mathrm{ppt}}^{2}\right)^{1 / 2}$, and the Voce equation becomes

$\sigma=\alpha G b M\left\{\left(k_{0} / f_{n s} k_{2}\right)\left[1-\exp \left(-M f_{n s} k_{2} \varepsilon^{p}\right)\right]\right\}^{1 / 2}$

and the work-hardening rate can be obtained as follows: 
$\theta_{\text {total }}=\left[\frac{\sigma}{\left(\sigma_{p p t}^{2}+\sigma^{2}\right)^{1 / 2}}\right] \cdot\left[\frac{(\alpha G b M)^{2} M k_{0}}{2 \sigma}-\frac{f_{n s} k_{2} M \sigma}{2}\right]$.

After differentiating with $\sigma$, we obtain

$$
\frac{d \theta_{\text {total }}}{d \sigma}=-\frac{\left(\alpha_{0} G b M\right)^{2} M k_{0} \sigma}{2\left(\sigma_{\mathrm{ppt}}^{2}+\sigma^{2}\right)^{3 / 2}}-\frac{f_{n s} M k_{2}}{2}\left[\frac{2 \sigma}{\left(\sigma_{\mathrm{ppt}}^{2}+\sigma^{2}\right)^{1 / 2}}-\frac{\sigma^{3}}{\left(\sigma_{\mathrm{ppt}}^{2}+\sigma^{2}\right)^{3 / 2}}\right] .
$$

Thus, we obtain

$$
\frac{d \theta_{\text {total }}}{d \sigma_{\text {total }}}=-\frac{(\alpha G b M)^{2} M k_{0}}{2\left(\sigma_{p p t}^{2}+\sigma^{2}\right)}-\frac{f_{n s} k_{2} M}{2}\left[2-\frac{\sigma^{2}}{\left(\sigma_{p p t}^{2}+\sigma^{2}\right)}\right] \text {. }
$$

When the stress reaches saturation (ultimate tensile strength), $\sigma>>\sigma_{p p t}$. Thus, equation (29) can be simplified as

$$
\frac{d \theta_{\text {total }}}{d \sigma_{\text {total }}}=-\frac{(\alpha G b M)^{2} M k_{0}}{2 \sigma^{2}}-\frac{f_{n s} k_{2} M}{2}=-\frac{M k_{0}}{2 \rho^{S}}-\frac{f_{n s} k_{2} M}{2}
$$

where $\rho^{S}$ is the saturated dislocation density, which can be determined from synchrotron radiation X-ray diffraction. According to equation (30), $f_{n s}$ can be obtained. All the model parameters and predicted critical necking strain for AlMgScZr alloy are listed in Table 4. Although the slope curve of the Alloy-NS sample is influenced by $k_{0}$ and $\rho^{S}$, the dominant parameters are $f_{n s}$ and $k_{2}$.

After determining all the parameters in the modified dislocation-based models (equations (14), (17), and (20)), the values predicted by these models can be evaluated. The model prediction also shows that the ductility decreases with the formation of shearable precipitates and increases again with the shearable precipitates becoming nonshearable precipitates for AlMgScZr alloy (Fig. 8). Moreover, the values predicted using equations (14), (17), and (20) agree well with the experimental results, as shown in Fig. 8. The underlying dislocation mechanisms behind the variation in ductility during precipitation for $\mathrm{AlMgScZr}$ alloy are discussed in the following section. 
Table 4 Parameters of the developed dislocation-based models and predicted critical necking strain for AlMgScZr alloy.

\begin{tabular}{ccccccccc}
\hline \multirow{2}{*}{ Samples } & $\theta_{0}(\mathrm{MPa})$ & $\frac{d \theta}{d \sigma_{\text {total }}}$ & $k_{0}\left(\mathrm{~m}^{2}\right)$ & $k_{1}\left(\mathrm{~m}^{-1}\right)$ & $k_{2}$ & $f_{s}$ & $f_{n s}$ & $\varepsilon_{c}$ \\
\hline AlMg & 2228 & -8.70 & - & $2.2 \times 10^{8}$ & 5.69 & - & - & 0.158 \\
Alloy-S & 3660 & -22.09 & - & $3.7 \times 10^{8}$ & 5.69 & 2.54 & - & 0.099 \\
Alloy-NS & - & -13.56 & $4.9^{*} 10^{15}$ & - & 5.69 & - & 1.13 & 0.144 \\
\hline
\end{tabular}

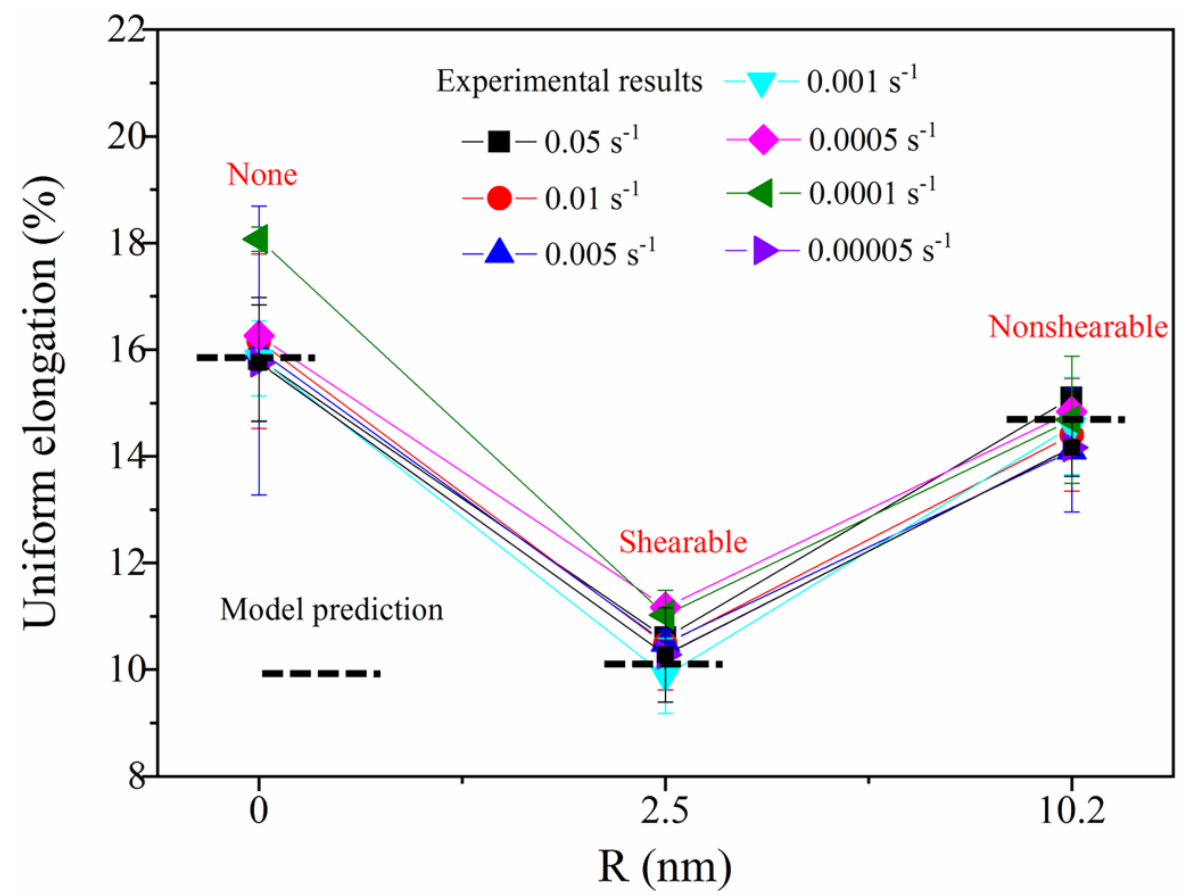

Fig. 8 Variations in ductility at different strain rates during the precipitation of shearable and nonshearable precipitates for AlMgScZr alloy as well as the corresponding model prediction.

\section{Discussion}

Our results show that, when shearable precipitates occur, the ductility significantly decreases for AlMgScZr alloy. However, when the shearable precipitates become nonshearable precipitates, the ductility notably increases (Fig. 8). The modified dislocation-based model prediction agrees well with the experimental results of AlMgScZr alloy (Fig. 8). Therefore, we conclude that the kinetics of dislocation 
density evolution revealed by $k_{2}, f_{s} k_{2}$, and $f_{n s} k_{2}$ parameters govern the strain hardening stage up to the point of macroscopic instability for AlMg, Alloy-S, and Alloy-NS samples. Although the predicted critical strain by equations (14), (17), and (20) contains $k_{0}$ or $k_{1}$, only $k_{2}, f_{s}$, and $f_{n s}$ appear in the pre-logarithmic factor and the other parameters fit logarithmically, indicating that the $k_{2}, f_{s}$, and $f_{n s}$ parameters govern the overall dependence of the necking strain on the model parameters. The $k_{2}, f_{s} k_{2}$, and $f_{n s} k_{2}$ parameters reflect the curve slope of AlMg, Alloy-S, and Alloy-NS samples, respectively (Fig. 5 (i)). The slope of the curve (Fig. 5 (i)) rapidly increases when shearable precipitates appear ( $k_{2}$ becomes $f_{s} k_{2}$, with $f_{s}>1$ ), indicating the enhancement of dynamic recovery rate of the Alloy-S sample. However, the slope decreases when the shearable precipitates become nonshearable precipitates $\left(f_{s} k_{2}\right.$ becomes $f_{n s} k_{2}$, with $f_{n s}<f_{s}$ ), indicating a decrease in the dynamic recovery rate. Therefore, the enhancement of strain hardening that results from reducing the slope of the curve (Fig. 5 (i)) inhibits the onset of necking for $\mathrm{AlMgScZr}$ alloy.

The work-hardening rate of the Alloy-S sample is much higher than that of the AlMg alloy, during the initial stage of plastic deformation (Fig. 5 (i)). However, the work-hardening rate significantly decreases with an increase in the deformation which is less than that in the AlMg sample after a certain extent of deformation. This is because the dislocation density of the Alloy-S sample increases dramatically at the initial stage of deformation and saturates faster than the AlMg sample (Fig. 11). A rapid increase in the dislocation density at the early stage of deformation of the Alloy-S sample results in a very high work-hardening rate. As the deformation of the Alloy-S sample increases, the rate of increase of the dislocation density decreases rapidly. Consequently, the work-hardening rate of the Alloy-S sample decreases significantly, and it is smaller than that of the AlMg alloy after a certain deformation. The variation in the dislocation density is due to the special precipitate-dislocation 
interaction. For the Alloy-S sample, the subsequent gliding dislocations are prone to move along the special plane when the dislocations present ahead shear the precipitates to form a special plane on precipitates, resulting in a localised deformation band along a single slip plane owing to its low motion resistance (Figs. 9 $(\mathrm{d}-\mathrm{g})$ and $\left.\left(\mathrm{d}^{\prime}-\mathrm{g}^{\prime}\right)\right)$. While for AlMg alloy, the dislocations are distributed homogeneously (Figs. 9 (a-c)). The shearable precipitates cannot trap the dislocations similar to the nonshearable precipitates through Orowan loops. Recent studies have shown that the planar slip caused by shearable precipitates can lead to dislocation pile-ups in these deformation bands, resulting in a significant increase in the local storage dislocation density [Poole et al., 2005; Xiao et al., 2005; Lefebvre et al., 2014; Tayon et al., 2019]. The dislocation pile-ups inside these slip bands will cause a higher local strain concentration. It can be seen that the $k_{1}$ of Alloy-S sample is higher than that of $\mathrm{AlMg}$ sample, indicating that a higher density of dislocations is stored (Table 4). The increase of $k_{1}$ is mainly attributed to the formation of slip bands with dislocation pile-ups. That is, the increase of $k_{1}$ can reflect the influence of local strain concentration caused by slip bands on dislocation storage. As more deformation bands with higher dislocation density are rapidly formed, a high driving force supplied by these dense dislocations can promote a higher dynamic recovery rate (Fig. 12) [Brown and Stobbs, 1971]. Thus, the slope of the work-hardening curve of the Alloy-S sample (Fig. 5 (i)) is much steeper than that of the AlMg alloy. In Table 4 , it can be seen $k_{2} f_{s}>k_{2}$ when shearable precipitates occur. Since the increase of dynamic recovery rate from AlMg to Alloy-S can be attributed to the formation of slip bands with dislocation pile-ups, the increase of $k_{2}$ to $k_{2} f_{s}$ can reflect the influence of local strain concentration caused by slip bands on dynamic recovery rate of dislocation.

In general, the $k_{1}$ and $k_{2}$ increases when shearable precipitates occur, which is due to the local strain concentration caused by slip bands. Since the ductility is mainly 
controlled by $k_{2}$, thus the ductility decreases via equations (14) and (17) when shearable precipitates occur.
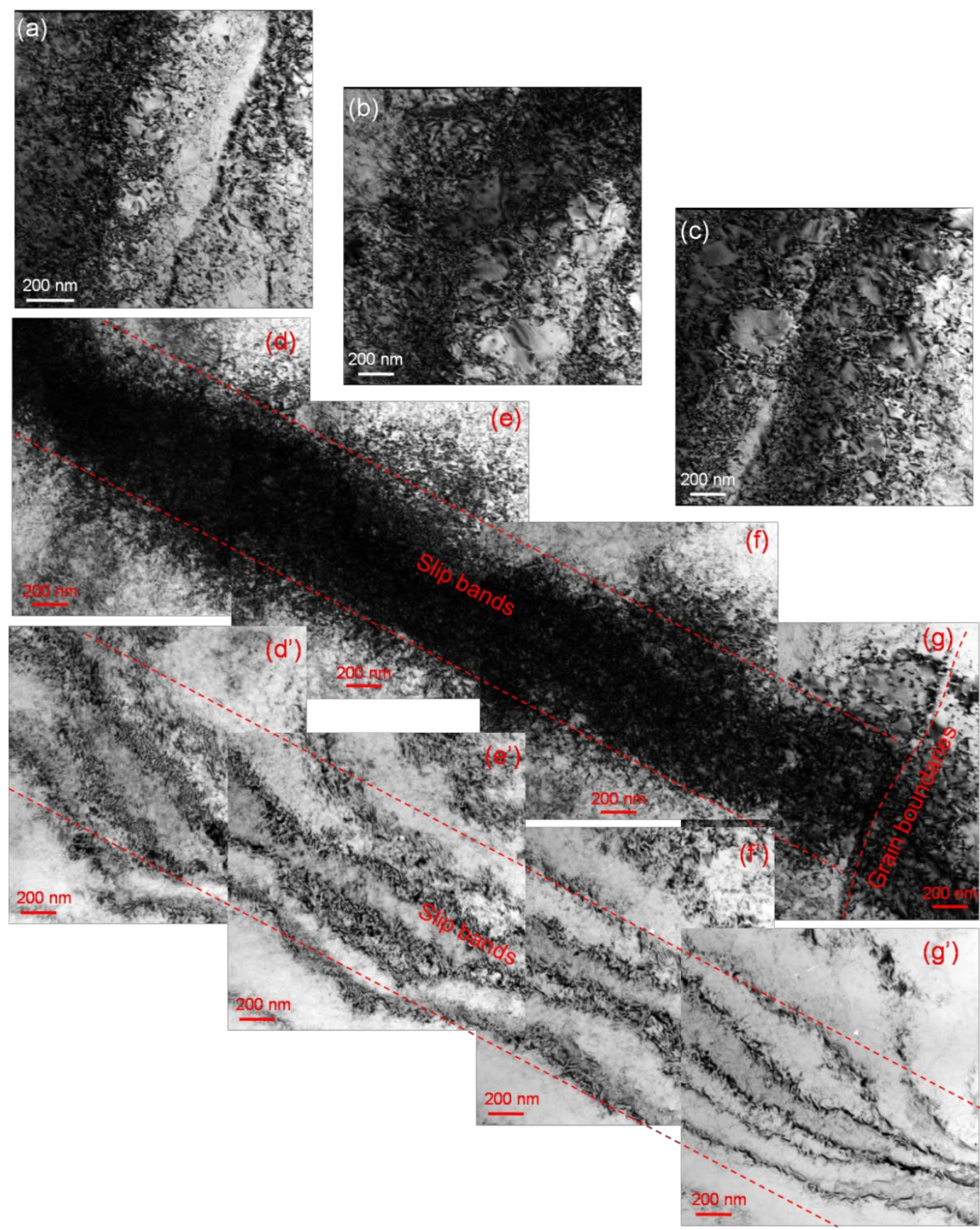

Fig. 9 Bright field TEM images of AlMg and Alloy-S samples after 5\% tensile strains: $(\mathrm{a}-\mathrm{c})$ uniform distributed dislocation of three different areas in AlMg alloy (the incident electron beam is parallel to [110]). (d-g) Banded dislocation structure (slip bands) intersecting the grain boundaries in Alloy-S (the incident electron beam is parallel to [110]). (d'-g') Corresponding dislocation structures of $(d-g)$ without special zone axis. 


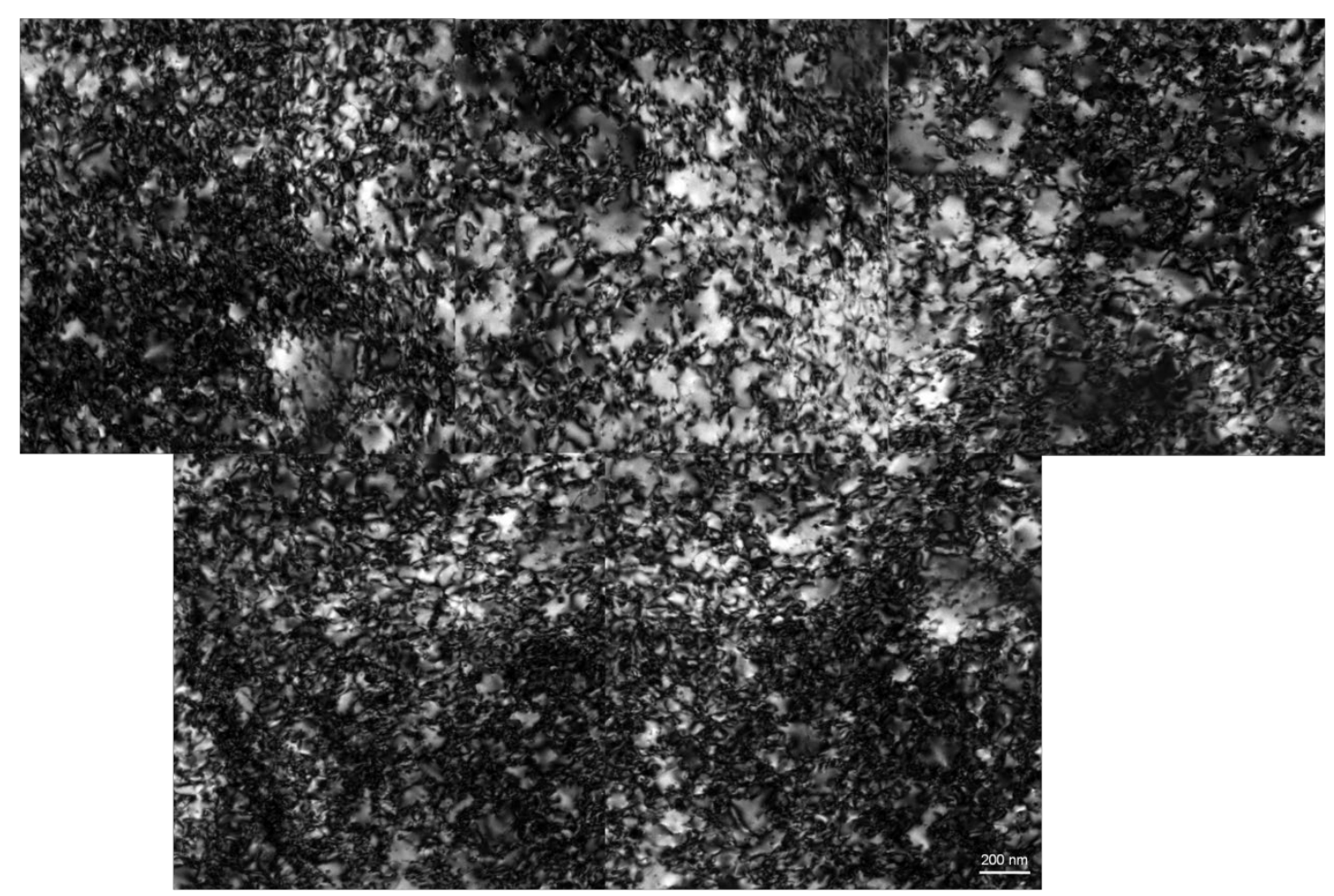

Fig. 10 Bright field TEM images of Alloy-NS samples after 5\% tensile strains. The dislocations distribute relative uniformly (the incident electron beam is parallel to $[110])$.

When the shearable precipitates become nonshearable precipitates, the rate at which the dislocation density of Alloy-NS increases is lower than that of Alloy-S (Fig. 11) at the early deformation stage; thus, the work-hardening rate of Alloy-NS is lower than that of Alloy-S (Fig. 5 (i)). As the deformation increases, the dislocation density of Alloy-NS increases faster than that of Alloy-S (Fig. 11), and the work-hardening rate of Alloy-NS exceeds that of Alloy-S after a certain extent of deformation (Fig. 5 (i)). For the Alloy-NS sample, the dislocation density increases and a number of Orowan loops gather around the nonshearable precipitates. The plastic relaxation mechanism may be activated in the form of primary Orowan dislocation loops decomposed into prismatic Orowan dislocation loops or cross-slip at the early stage of deformation (Fig. 12) [Brown and Stobbs, 1971]. These plastic relaxation mechanisms always accompany dislocation multiplication during the entire deformation process; thus, the dislocations are distributed uniformly (Fig. 10). The driving force supplied by the dislocations for recovery is smaller than that of the Alloy-S sample. Therefore, 
the dynamic recovery rate of the Alloy-NS sample is lower than that of the Alloy-S sample; thus, the slope of the work-hardening rate versus flow stress is flatter. Thus, the $f_{n s} k_{2}$ of Alloy-NS sample is smaller than $f_{s} k_{2}$ of Alloy-S, and the ductility of Alloy-NS sample is higher than that of Alloy-S via equation (20). However, since many Orowan loops can be accumulated around the nonshearable precipitates, a relative higher local strain concentration will appear around the nonshearable precipitates compared with the AlMg alloy without precipitates. Thus the $f_{n s} k_{2}$ in KM model of Alloy-NS is slightly higher than that $k_{2}$ of AlMg alloy, and the ductility of Alloy-NS sample is lower than that of AlMg alloy via equation (20).
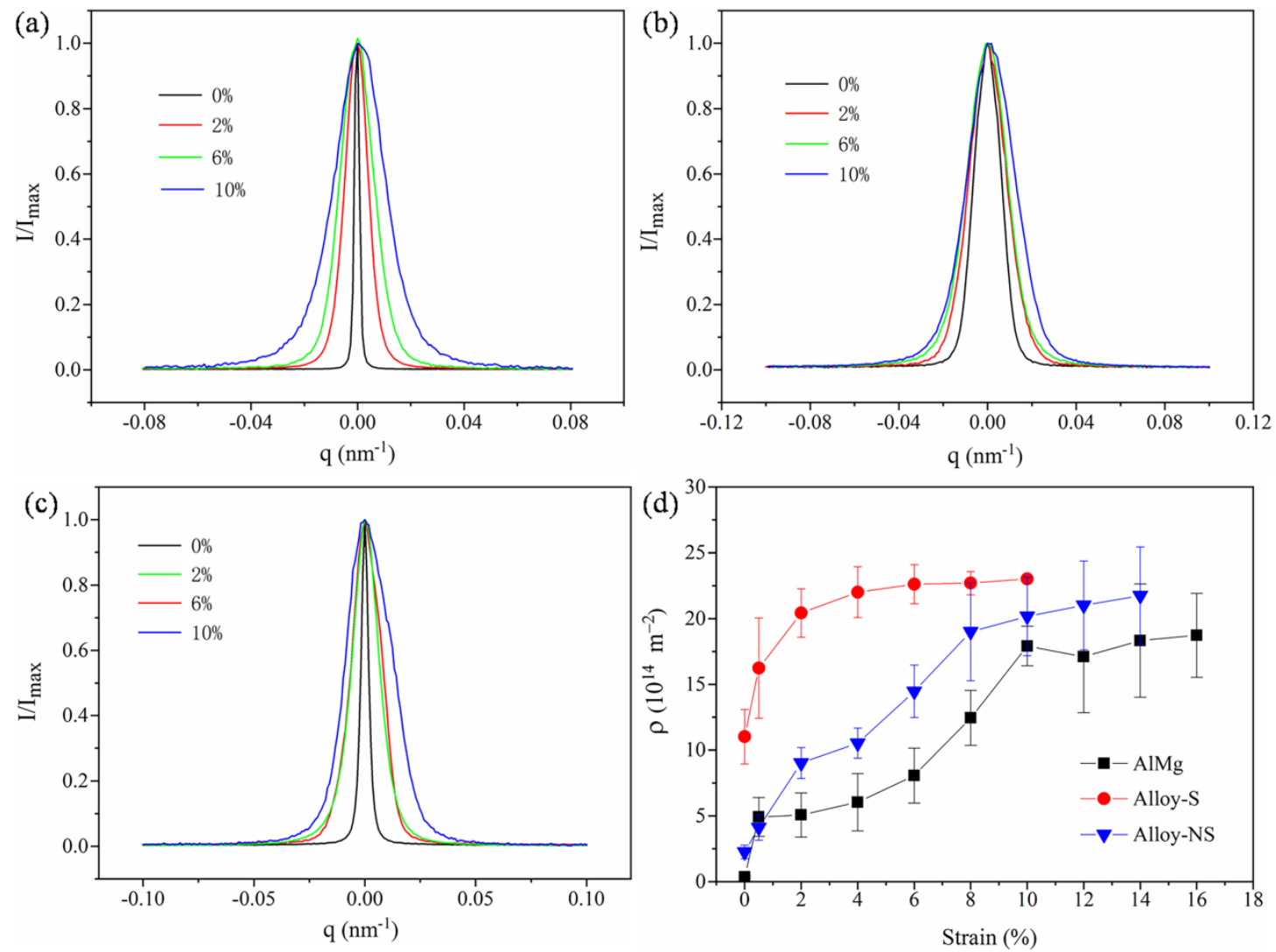

Fig. 11 (200) peaks at different strains for (a) AlMg, (b) Alloy-S, and (c) Alloy-NS. (d) Variations in dislocation density versus strain for AlMg, Alloy-S, and Alloy-NS.

Unlike the Alloy-NS sample with nonshearable precipitates, the dislocation density of the Alloy-S sample with shearable precipitates significantly increases and saturates rapidly in the same strain range. The interaction of the shearable precipitates 
and dislocations results in the formation of dislocation bands with higher dislocation density for the Alloy-S sample, while the dislocations are uniformly distributed during the deformation of the Alloy-NS sample (Figs. 9, 10 and 12). Moreover, the dislocations easily interact with the precipitates during their movement for Alloy-S sample due to the shearable precipitates having a smaller interspacing. The drag effect would be higher in Alloy-S specimen, which can promote the higher accumulation rate of dislocation locally and lead to a higher density of dislocation accumulation. Thus, the shearable precipitates with smaller precipitate interspacing could aggravate the dislocation pile-ups inside the slip bands. The higher dislocation density accumulation and inhomogeneous distribution in the deformation bands easily result in a higher dynamic recovery rate that results in decreased ductility for Alloy-S sample. This dynamic recovery rate decreases when shearable precipitates become nonshearable precipitates, leading to an increase in ductility. The proposed dislocation-based approach is based on the evolution of the dislocation structure and clearly demonstrates and predicts the ductility variation in precipitation hardening AlMgScZr alloy. By revealing the fundamental nature of the different dislocation-precipitate interactions, the physical mechanisms for controlling ductility during precipitation for $\mathrm{AlMgScZr}$ alloy can be understood. This provides an important guidance for designing alloy systems with enhanced mechanical properties. 


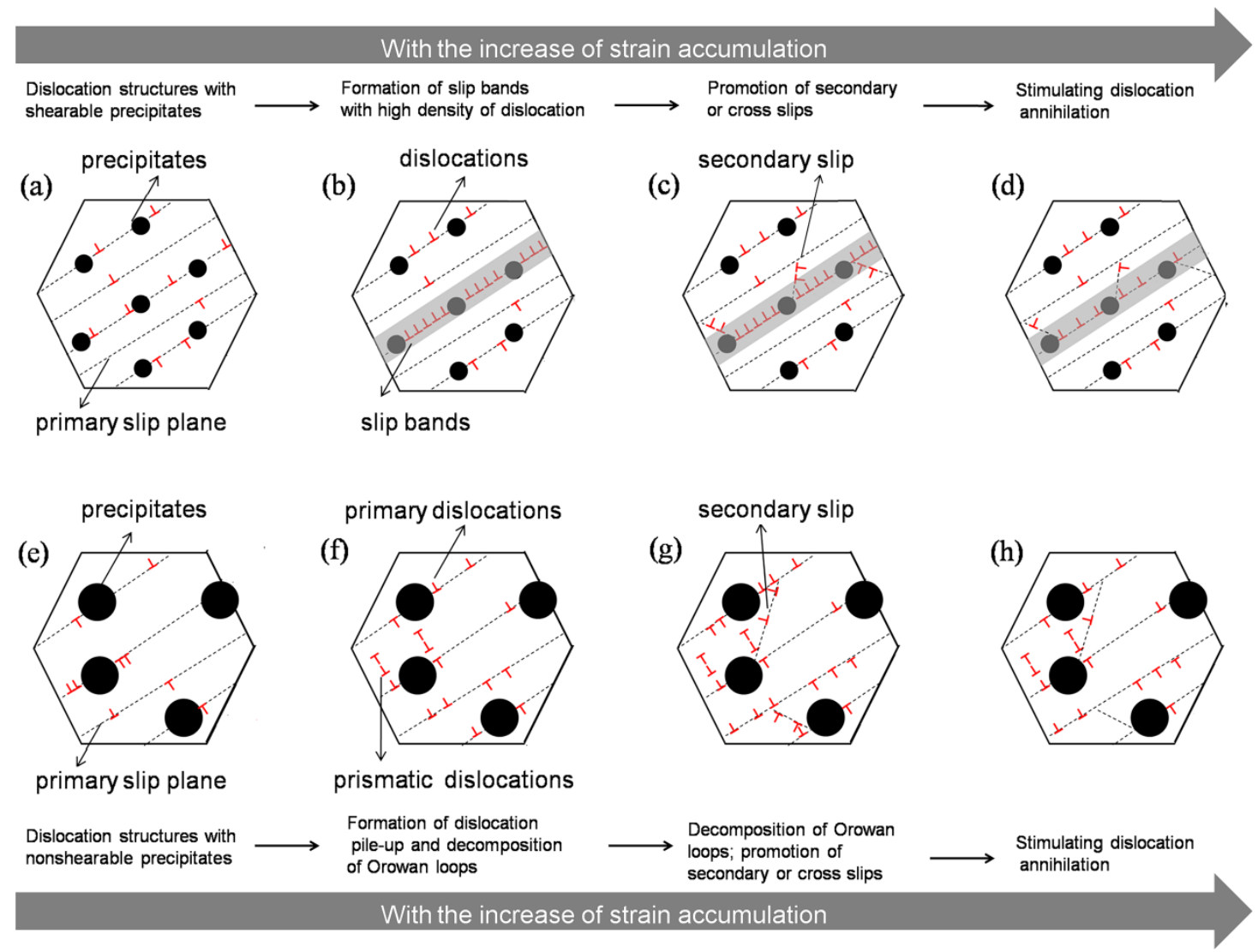

Fig. 12 Schematic illustration of the dislocation structure evolution of $(a-d)$ the Alloy-S and (e-h) Alloy-NS samples during deformation. With the increase of deformation, multiple slip bands are formed, and the dislocation is mainly distributed inside these slip bands for the Alloy-S sample. These pile-up dislocations easily promote secondary or cross slips, leading to a relative higher dynamic recovery rate. In contrast, the dislocation distributes uniformly, and local softening phenomenon due to decomposition of Orowan loops is observed during the strain accumulation for the Alloy-NS sample. Although the dislocation density is always in the increasing trend, the increase rate is much lower than that of the Alloy-S sample. Therefore, the degree of dislocation pile-up is weaker than that of the Alloy-S alloy, resulting in a lower dynamic recovery rate.

\section{Conclusions}

In this study, the influence of shearable and nonshearable precipitates on ductility is investigated for $\mathrm{AlMgScZr}$ alloy. A modified dislocation-based approach considering shearable and nonshearable precipitates is proposed. Compared with the classical Considère or Hart criteria, this modified dislocation-based approach can 
predict the variation of ductility during precipitation for $\mathrm{AlMgScZr}$ alloy by considering the intrinsic variables directly connected to the dislocation structure. Experimentally, by revealing the influence of shearable and nonshearable precipitates on dislocation motion and multiplication, the dislocation mechanisms for dominating the ductility during precipitation are demonstrated for AlMgScZr alloy. The qualitative and quantitative analyses are provided and can be summarised as follows:

(1) The ductility decreases during the formation of shearable precipitates and increases again when shearable precipitates become nonshearable precipitates for AlMgScZr alloy. A modified dislocation-based approach considering precipitates is proposed to model the variation in ductility during precipitation. This modified dislocation-based approach can model the variation of ductility during precipitation, as well as predict the plastic instability point for AlMgScZr alloy.

(2) The modified dislocation-based model demonstrates that it is the kinetics of dislocation density evolution revealed by dynamic recovery rate of dislocations governs the strain hardening stage up to the point of macroscopic instability for $\mathrm{AlMgScZr}$ alloy, which is reflected by the slope of the curve representing the work-hardening rate versus flow stress. The influence of precipitates on ductility is mainly achieved by changing the dynamic recovery rate of dislocations for this alloy. The dynamic recovery rate of dislocations increases with the formation of shearable precipitates for AlMgScZr alloy, while it decreases with the shearable precipitates being replaced by nonshearable precipitates.

(3) The interaction of shearable precipitates and dislocations leads to the formation of dislocation bands with higher dislocation density for AlMgScZr alloy with shearable precipitates, while the dislocations are distributed uniformly during deformation in the AlMgScZr alloy with nonshearable precipitates. The higher dislocation density accumulation and inhomogeneous distribution in the deformation bands promote the highest dynamic recovery rate of dislocations for $\mathrm{AlMgScZr}$ alloys with shearable 
precipitates, eventually leading to the lowest ductility.

\section{Acknowledgments}

This work is financially supported by the National Natural Science Foundation of China [Grant Nos. 51971137, 11875192, and U1930101] and the Conseil Regional du Nord-Pas de Calais and the European Regional Development Fund (ERDF). Yubin Ke is also grateful for the funding from the Natural Science Foundation of Guangdong Province (CN) [Grant No. 2018A030313728] and the National Key Research and Development Program of China [Grant No. 2016YFA0401501]. We would also like to thank the faculty of BL14B1 beamline at the Shanghai Synchrotron Radiation Facility for their help with synchrotron experiments. Han Chen is grateful for the support from Tescan, China.

\section{Reference}

Antolovich, S.D., Armstrong, R.W., 2014. Plastic strain localization in metals: origins and consequences. Prog. Mater. Sci. 59, 1-160. https://doi.org/10.1016/10.1016/j.pmatsci.2013.06.001. Ardell, A.J., 1985. Precipitation hardening. Metall. Trans. A 16A, 2131-2165. https://doi.org/10.1007/bf02670416.

Ashcroft, N.W., Lekner, J., 1966. Structure and resistivity of liquid metals. Phys. Rev. 145, 83-90. https://doi.org/10.1103/PhysRev.145.83.

Borbély, A., Groma, I., 2001. Variance method for the evaluation of particle size and dislocation density from x-ray Bragg peaks. Appl. Phys. Lett. 79, 1772-1774. https://doi.org/10.1063/1.1404134.

Borbély, A., Ungár, T., 2012. X-ray line profiles analysis of plastically deformed metals. CR Phys. 13, 293-306. https://doi.org/10.1016/j.crhy.2011.12.004.

Brown, L.M., Stobbs, W.M., 1971. The work-hardening of copper-silica, Philos. Mag. 23, 1201-1233. https://doi.org/10.1080/14786437108217406.

Cheng, L.M., Poole, W.J., Embury, J.D., Lloyd, D.J., 2003. The influence of precipitation on the work-hardening behavior of the aluminum alloys AA6111 and AA7030. Metall. Mater. Trans. A 34A, 2473-2481. https://doi.org/10.1007/s1 1661-003-0007-2.

Clouet, E., Barbu, A., Laé, L., Martin, G., 2005. Precipitation kinetics of $\mathrm{Al}_{3} \mathrm{Zr}$ and $\mathrm{Al}_{3} \mathrm{Sc}$ in aluminum alloys modeled with cluster dynamics. Acta Mater. 53, 2313-2325. 
https://doi.org/10.1016/j.actamat.2005.01.038.

Considère, M., 1885. Mémoire sur l'emploi du fer et de l'acier dans les constructions, Vue Ch. Dunod,

Cottrell, A.H., Bilby, B.A., 1949. Dislocation theory of yielding and strain ageing of iron, Proc. Phys. Soc. A 62, 49-62. https://doi.org/10.1088/0370-1298/62/1/308.

Decreus, B., Deschamps, A., De Geuser, F., Donnadieu, P., Sigli, C., Weyland, M., 2013. The influence of $\mathrm{Cu} / \mathrm{Li}$ ratio on precipitation in Al-Cu-Li-x alloys. Acta Mater. 61, 2207-2218. https://doi.org/10.1016/j.actamat.2012.12.041.

Ding, Z.Y., He, Q.F., Wang, Q., Yang, Y., 2018. Superb strength and high plasticity in laves phase rich eutectic medium-entropy-alloy nanocomposites. Int. J. Plasticity 106, 57-72. https://doi.org/10.1016/j.ijplas.2018.03.001.

Estrin Y., 1996. Dislocation-density-related constitutive modeling, Unified Constitutive Laws of Plastic Deformation, 69-106. https://doi.org/10.1016/B978-012425970-6/50003-5.

Estrin, Y., Kubin, L.P., 1990. Collective dislocation behaviour in dilute alloys and the Portevin-Le Chatelier effect. J. Mech. Behav. Mater. 2, 255-292. https://doi.org/10.1515/JMBM.1989.2.3-4.255.

Estrin, Y., Mecking, H., 1984. A unified phenomenological description of work hardening and creep based on one-parameter models. Acta Metall. 32, 57-70. https://doi.org/10.1016/0001-6160(84)90202-5.

Fan, H.D., Ngan, A.H.W., Gan, K.F., El-Awady, J.A., 2018. Origin of double-peak precipitation hardening in metallic alloys. Int. J. Plasticity 111, 152-167. https://doi.org/10.1016/j.ijplas.2018.07.016.

Fazeli, F., Poole, W.J., Sinclair, C.W., 2008. Modeling the effect of $\mathrm{Al}_{3} \mathrm{Sc}$ precipitates on the yield stress and work hardening of an Al-Mg-Sc alloy. Acta Mater. 56, 1909-1918. https://doi.org/10.1016/j.actamat.2007.12.039.

Fuller, C.B., Seidman, D.N., Dunand, D.C., 2003. Mechanical properties of Al(Sc,Zr) alloys at ambient and elevated temperatures. Acta Mater. 51, 4803-4814. https://doi.org/10.1016/s1359-6454(03)00320-3.

Fuller, C.B., Murray, J.L., Seidman, D.N., 2005. Temporal evolution of the nanostructure of $\mathrm{Al}(\mathrm{Sc}, \mathrm{Zr})$ alloys: Part I - Chemical compositions of $\mathrm{Al}_{3}\left(\mathrm{Sc}_{1-\mathrm{x}} \mathrm{Zr}_{\mathrm{x}}\right)$ precipitates. Acta Mater. 53, 5401-5413. https://doi.org/10.1016/j.actamat.2005.08.016.

Ghosh, A.K., 1977. Tensile instability and necking in materials with strain hardening and strain-rate hardening. Acta Metall. 25, 1413-1424. https://doi.org/10.1016/0001-6160(77)90072-4. Gladman, T., 1999. Precipitation hardening in metals. Mater. Sci. Tech. 15, 30-36. https://doi.org/10.1179/026708399773002782.

Hart, E.W., 1967. Theory of the tensile test. Acta Metall. 15, 351-355. https://doi.org/10.1016/0001-6160(67)90211-8.

He, B.B., Hu, B., Yen, H.W., Cheng, G.J., Wang, Z.K., Luo, H.W., Huang, M.X., 2017. High dislocation density-induced large ductility in deformed and partitioned steels. Science 357, 1029-1032. https://doi.org/10.1126/science.aan0177.

Huang, X.X., Hansen, N., Tsuji, N., 2006. Hardening by annealing and softening by deformation in nanostructured metals. Science 312, 249-251. https://doi.org/10.1126/science.1124268.

Huang, C.X., Wang, Y.F., Ma, X.L., Yin, S., Höeppel, H.W., Göken, M., Wu, X.L., Gao, H.J., Zhu, Y.T., 2018. Interface affected zone for optimal strength and ductility in heterogeneous laminate. Mater. Today 21, 713-719. https://doi.org/10.1016/j.mattod.2018.03.006. 
Hull. D., Bacon, D.J., 2011. Introduction to dislocations, fifth ed. Elsevier.

Hutchinson, J.W., Neale, K.W., 1977. Influence of strain-rate sensitivity on necking under uniaxial tension. Acta Metall. 25, 839-846. https://doi.org/10.1016/0001-6160(77)90168-7.

Jiang, S.H., Wang, H., Wu, Y., Liu, X.J., Chen, H.H., Yao, M.J., Gault, B., Ponge, D., Raabe, D., Hirata, A., Chen, M.W., Wang, Y.D., Lu, Z.P., 2017. Ultrastrong steel via minimal lattice misfit and high-density nanoprecipitation. Nature 544, 460-464. https://doi.org/10.1038/nature22032.

Iwamura, S., Miura, Y., 2004. Loss in coherency and coarsening behavior of $\mathrm{Al}_{3} \mathrm{Sc}$ precipitates. Acta Mater. 52, 591-600. https://doi.org/10.1016/j.actamat.2003.09.042.

Kalácska, S., Groma, I., Borbély, A., Ispánovity, P.D., 2017. Comparison of the dislocation density obtained by HR-EBSD and X-ray profile analysis. Appl. Phys. Lett. 110, 091912. https://doi.org/10.1063/1.4977569.

Ke, Y.B., He, C.Y., Zheng, H.B., Geng, Y.S., Fu, J.Y., Zhang, S.K., Hu, H.T., Wang, S.L., Zhou, B., Wang, F.W., Tao, J.Z., 2018. The time-of-flight small-angle neutron spectrometer at China $\begin{array}{llllll}\text { spallation neutron } & \text { source. } & \text { Neutron } & \text { News }\end{array}$ https://doi.org/10.1080/10448632.2018.1514197.

Kendig, K.L., Miracle, D.B., 2002. Strengthening mechanisms of an Al-Mg-Sc-Zr alloy. Acta Mater. 50, 4165-4175. https://doi.org/10.1016/s1359-6454(02)00258-6.

Kim, H.S., Estrin, Y., 2001. Ductility of ultrafine grained copper. Appl. Phys. Lett. 79, 4115-4117. https://doi.org/10.1063/1.1426697.

Kim, S.H., Kim, H., Kim, N.J., 2015. Brittle intermetallic compound makes ultrastrong low-density steel with large ductility. Nature 518, 77-79. https://doi.org/ 10.1038/nature14144.

Knipling, K.E., Karnesky, R.A., Lee, C.P., Dunand, D.C., Seidman, D.N., 2010. Precipitation evolution in $\mathrm{Al}-0.1 \mathrm{Sc}, \mathrm{Al}-0.1 \mathrm{Zr}$ and $\mathrm{Al}-0.1 \mathrm{Sc}-0.1 \mathrm{Zr}$ (at.\%) alloys during isochronal aging. Acta Mater. 58, 5184-5195. https://doi.org/10.1016/j.actamat.2010.05.054.

Koch, C.C., Morris, D.G., Lu, K., Inoue, A., 1999. Ductility of nanostructured materials. MRS Bull. 24, 54-58. https://doi.org/10.1557/s0883769400051551.

Kocks, U.F., 1976. Laws for work-hardening and low-temperature creep. J. Eng. Mater. Technol. 98, 76-85. https://doi.org/10.1115/1.3443340.

Kubin, L.P., Estrin, Y., 1985. The Portevin-Le Chatelier effect in deformation with constant stress rate. Acta Metall. 33, 397-407. https://doi.org/10.1016/0001-6160(85)90082-3.

Kubin, L.P., Estrin, Y., 1990. Evolution of dislocation densities and the critical conditions for the Portevin-Le Chatelier effect. Acta Metall. Mater. 38, 697-708. https://doi.org/10.1016/0956-7151(90)90021-8.

Kubin, L.P., Estrin, Y., 1991. Plastic instabilities: phenomenology and theory. Mater. Sci. Eng. A 137, 125-134. https://doi.org/10.1016/0921-5093(91)90326-I.

Lai, J., Zhang, Z., Chen, X.G., 2013. Precipitation strengthening of $\mathrm{Al}-\mathrm{B}_{4} \mathrm{C}$ metal matrix composites alloyed with Sc and Zr. J. Alloy. Compd. 552, 227-235. https://doi.org/ 10.1016/j.jallcom.2012.10.096.

Lei, Z.F., Liu, X.J., Wu, Y., Wang, H., Jiang, S.H., Wang, S.D., Hui, X.D., Wu, Y.D., Gault, B., Kontis, P., Raabe, D., Gu, L., Zhang, Q.H., Chen, H.W., Wang, H.T., Liu, J.B., An, K., Zeng, Q.S., Nieh, T.G., Lu, Z.P., 2018. Enhanced strength and ductility in a high-entropy alloy via ordered oxygen complexes. Nature 563, 546-550. https://doi.org/10.1038/s41586-018-0685-y.

Lefebvre, W., Masquelier, N., Houard, J., Patte, R., Zapolsky, H., 2014. Tracking the path of dislocations across ordered $\mathrm{Al}_{3} \mathrm{Zr}$ nano-precipitates in three dimensions. Scr. Mater. 70, 43-46. https://doi.org/10.1016/j.scriptamat.2013.09.014.

Li, R., Wang, M., Li, Z., Cao, P., Yuan, T., Zhu, H., 2020. Developing a high-strength Al-Mg-Si-Sc-Zr alloy for selective laser melting: crack-inhibiting and multiple strengthening mechanisms. Acta Mater. 193, 83-98. https://doi.org/10.1016/j.actamat.2020.03.060. 
Li, S.H., Han, W.Z., Li, J., Ma, E., Shan, Z.W., 2017a. Small-volume aluminum alloys with native oxide shell deliver unprecedented strength and toughness. Acta Mater. 126, 202-209. https://doi.org/10.1016/j.actamat.2016.12.055.

Li, X.P., Ji, G., Chen, Z., Addad, A., Wu, Y., Wang, H.W., Vleugels, J., Van Humbeeck, J., Kruth, J.P., 2017b. Selective laser melting of nano-TiB 2 decorated AlSi10Mg alloy with high fracture strength and ductility. Acta Mater. 129, 183-193. https://doi.org/10.1016/j.actamat.2017.02.062.

Li, Z.M., Pradeep, K.G., Deng, Y., Raabe, D., Tasan, C.C., 2016. Metastable high-entropy dual-phase alloys overcome the strength-ductility trade-off. Nature 534, 227-230. https://doi.org/10.1038/nature17981.

Lindner, P., Zemb, T., 1991. Neutron, X-ray and light scattering: introduction to an investigative tool for colloidal and polymeric systems. North Holland, Amsterdam.

Liu, G., Sun, J., Nan, C.W., Chen, K.H., 2005. Experiment and multiscale modeling of the coupled influence of constituents and precipitates on the ductile fracture of heat-treatable aluminum alloys. Acta Mater. 53, 3459-3468. https://doi.org/10.1016/j.actamat.2005.04.002.

Liu, G., Zhang, G.J., Jiang, F., Ding, X.D., Sun, Y.J., Sun, J., Ma, E., 2013. Nanostructured high-strength molybdenum alloys with unprecedented tensile ductility. Nat. Mater. 12, 344-350. https://doi.org/10.1038/nmat3544.

Luca, A.D., Seidman, D.N., Dunand, D.C., 2019. Effects of Mo and Mn microadditions on strengthening and over-aging resistance of nanoprecipitation-strengthened Al-Zr-Sc-Er-Si alloys. Acta Mater. 165, 1-14. https://doi.org/10.1016/j.actamat.2018.11.031.

Ma, K.K., Wen, H.M., Hu, T., Topping, T.D., Isheim, D., Seidman, D.N., Lavernia, E.J., Schoenung, J.M., 2014. Mechanical behavior and strengthening mechanisms in ultrafine grain precipitation-strengthened aluminum alloy. Acta Mater. 62, 141-155. https://doi.org/10.1016/j.actamat.2013.09.042.

Mathon, M.H., Barbu, A., Dunstetter, F., Maury, F., Lorenzelli, N., de Novion, C.H., 1997. Experimental study and modelling of copper precipitation under electron irradiation in dilute $\mathrm{FeCu}$ binary alloys. J. Nucl. Mater. 245, 224-237. https://doi.org/10.1016/s0022-3115(97)00010-x.

Mathon, M.H., de Carlan, Y., Geoffroy, G., Averty, X., Alamo, A., de Novion, C.H., 2003. A SANS investigation of the irradiation-enhanced a-a' phases separation in 7-12 $\mathrm{Cr}$ martensitic steels. J. Nucl. Mater. 312, 236-248. https://doi.org/10.1016/s0022-3115(02)01630-6.

Mathon, M.H., Perrut, M., Zhong, S.Y., de Carlan, Y., 2012. Small angle neutron scattering study of martensitic/ferritic ODS alloys. J. Nucl. Mater. 428, 147-153. https://doi.org/10.1016/j.jnucmat.2011.12.010.

Marquis, E.A., Seidman, D.N., 2005. Coarsening kinetics of nanoscale $\mathrm{Al}_{3} \mathrm{Sc}$ precipitates in an Al-Mg-Sc alloy. Acta Mater. 53, 4259-4268. https://doi.org/10.1016/j.actamat.2005.05.025.

McCormick, P.G., 1972. A model for the Portevin-Le Chatelier effect in substitutional alloys. Acta Metall. 20, 351-354. https://doi.org/10.1016/0001-6160(72)90028-4.

Ming, K.S., Bi, X.F., Wang, J., 2018. Realizing strength-ductility combination of coarse-grained A10.2 Co1.5CrFeNi1.5Ti0.3 alloy via nano-sized, coherent precipitates. Int. J. Plasticity 100, 177-191. https://doi.org/10.1016/j.ijplas.2017.10.005.

Ovid'ko, I.A., Valiev, R.Z., Zhu, Y.T., 2018. Review on superior strength and enhanced ductility of metallic nanomaterials. Prog. Mater. Sci. 94, 462-540. https://doi.org/10.1016/j.pmatsci.2018.02.002.

Perrard, F., Deschamps, A., Bley, F., Donnadieu, P., Maugis, P., 2006. A small-angle neutron scattering study of fine-scale $\mathrm{NbC}$ precipitation kinetics in the $a-\mathrm{Fe}-\mathrm{Nb}-\mathrm{C}$ system. J. App. 
Crystallog. 39, 473-482. https://doi.org/10.1107/s002188980601301x.

Poole, W.J., Wang, X., Lloyd, D.J., Embury, J.D., 2005. The shearable-non-shearable transition in Al-Mg-Si-Cu precipitation hardening alloys: implications on the distribution of slip, work hardening and fracture. Philos. Mag. 85, 3113-3135. https://doi.org/10.1080/14786430500154935.

Robson, J.D., 2004. A new model for prediction of dispersoid precipitation in aluminium alloys containing zirconium and scandium. Acta Mater. 52, 1409-1421. https://doi.org/10.1016/j.actamat.2003.11.023.

Sears, V.F., 1992. Neutron scattering lengths and cross sections. Neutron News. 3, 26-37. https://doi.org/10.1080/10448639208218770.

Shao, C.W., Zhang, P., Zhu, Y.K., Zhang, Z.J., Tian, Y.Z., Zhang, Z.F., 2018. Simultaneous improvement of strength and plasticity: Additional work-hardening from gradient microstructure. Acta Mater. 145, 413-428. https://doi.org/10.1016/j.actamat.2017.12.028.

Sun, W.W., Zhu, Y.M., Marceau, R., Wang, L.Y., Zhang, Q., Gao, X., Hutchinson, C., 2019. Precipitation strengthening of aluminum alloys by room-temperature cyclic plasticity. Science 363, 972-975. https://doi.org/10.1126/science.aav7086.

Taendl, J., Orthacker, A., Amenitsch, H., Kothleitner, G., Poletti, C., 2016. Influence of the degree of scandium supersaturation on the precipitation kinetics of rapidly solidified Al-Mg-Sc-Zr alloys. Acta Mater. 117, 43-50. https://doi.org/10.1016/j.actamat.2016.07.001.

Tayon, W.A., Nygren, K.E., Crooks, R.E., Pagan, D.C., 2019. In-situ study of planar slip in a commercial aluminum-lithium alloy using high energy X-ray diffraction microscopy. Acta Mater. 173, 231-241. https://doi.org/10.1016/j.actamat.2019.04.030.

Teixeira, J.D.C., Bourgeois, L., Sinclair, C.W., Hutchinson, C.R., 2009. The effect of shear-resistant, plate-shaped precipitates on the work hardening of $\mathrm{Al}$ alloys: Towards a prediction of the strength-elongation correlation. Acta Mater. 57, 6075-6089. https://doi.org/10.1016/j.actamat.2009.08.034.

Ungár, T., Borbély, A. (1996). The effect of dislocation contrast on x-ray line broadening: a new approach to line profile analysis. Appl. Phys. Lett. 69, 3173-3175. https://doi.org/10.1063/1.117951.

van Dalen, M.E., Dunand, D.C., Seidman, D.N., 2006. Nanoscale precipitation and mechanical properties of Al-0.06 at.\% Sc alloys microalloyed with $\mathrm{Yb}$ or Gd. J. Mater. Sci. 41, 7814-7823. https://doi.org/10.1007/s10853-006-0664-9.

Van den Beukel, A., 1975. Theory of the effect of dynamic strain aging on mechanical properties. Phys. Stat. Sol. (a) 30, 197-206. https://doi.org/10.1002/pssa.2210300120.

Vinogradov, A., Yasnikov, I.S., Matsuyama, H., Uchida, M., Kaneko, Y., Estrin, Y., 2016. Controlling strength and ductility: Dislocation-based model of necking instability and its verification for ultrafine grain 316L steel. Acta Mater. 106, 295-303. https://doi.org/10.1016/j.actamat.2016.01.005.

Vo, N.Q., Dunand, D.C., Seidman, D.N., 2014. Improving aging and creep resistance in a dilute Al-Sc alloy by microalloying with $\mathrm{Si}, \mathrm{Zr}$ and Er. Acta Mater. 63, 73-85. https://doi.org/10.1016/j.actamat.2013.10.008.

Voorhees, P.W., 2006. Alloys: Scandium overtakes zirconium. Nat. Mater. 5, 435-436. https://doi.org/10.1038/nmat1663.

Wang, Y.M., Chen, M.W., Zhou, F.H., Ma, E., 2002. High tensile ductility in a nanostructured metal. Nature 419, 912-915. https://doi.org/10.1038/nature01133. 
Wang, Y.M., Hamza, A.V., Ma, E., 2006. Temperature-dependent strain rate sensitivity and activation volume of nanocrystalline Ni. Acta Mater. 54, 2715-2726. https://doi.org/10.1016/j.actamat.2006.02.013.

Wang, Y.M., Ma, E., 2004. Three strategies to achieve uniform tensile deformation in a nanostructured metal. Acta Mater. 52, 1699-1709. https://doi.org/10.1016/j.actamat.2003.12.022.

Wu, G., Chan, K.C., Zhu, L.L., Sun, L.G., Lu, J., 2017. Dual-phase nanostructuring as a route to high-strength magnesium alloys. Nature 545, 80-83. https://doi.org/ 10.1038/nature21691.

Wu, X.L., Yang, M.X., Yuan, F.P., Wu, G.L., Wei, Y.J., Huang, X.X., Zhu, Y.T., 2015. Heterogeneous lamella structure unites ultrafine-grain strength with coarse-grain ductility. Proc. Natl. Acad. Sci. 112, 14501-14505. https://doi.org/10.1073/pnas.1517193112.

Wu, Z.X., Ahmad, R., Yin, B.L., Sandlöebes, S., Curtin, W.A., 2018. Mechanistic origin and prediction of enhanced ductility in magnesium alloys. Science 359, 447-452. https://doi.org/10.1126/science.aap8716.

Wu, Z.X., Curtin, W.A., 2015. The origins of high hardening and low ductility in magnesium. Nature 526, 62-67. https://doi.org/10.1038/nature15364.

Xiao, L., Chen, D.L., Chaturvedi, M.C., 2005. Shearing of $\gamma^{\prime \prime}$ precipitates and formation of planar slip bands in Inconel 718 during cyclic deformation. Scr. Mater. 52, 603-607. https://doi.org/10.1016/j.scriptamat.2004.11.023.

Xu, S.S., Zhao, Y., Chen, D., Sun, L.W., Chen, L., Tong, X., Liu, C.T., Zhang, Z.W., 2019. Nanoscale precipitation and its influence on strengthening mechanisms in an ultra-high strength low-carbon steel. Int. J. Plasticity 113, 99-110. https://doi.org/10.1016/j.ijplas.2018.09.009.

Yang, P.J., Li, Q.J., Han, W.Z., Li, J., Ma, E., 2019. Designing solid solution hardening to retain uniform ductility while quadrupling yield strength. Acta Mater. 179, 107-118. https://doi.org/10.1016/j.actamat.2019.08.024.

Yang, T.Y., Wen, W., Yin, G.Z., Li, X.L., Gao, M., Gu, Y.L., Li, L., Liu, Y., Lin, H., Zhang, X.M., Zhao, B., Liu, T.K., Yang, Y.G., Li, Z., Zhou, X.T., Gao, X.Y., 2015. Introduction of the X-ray diffraction beamline of SSRF. Nucl. Sci. Tech. 26, 020101. https://doi.org/ 10.13538/j.1001-8042/nst.26.20101.

Yang, T., Zhao, Y.L., Tong, Y., Jiao, Z.B., Wei, J., Cai, J.X., Han, X.D., Chen, D., Hu, A., Kai, J.J., Lu, K., Liu, Y., Liu, C.T., 2018. Multicomponent intermetallic nanoparticles and superb mechanical behaviors of complex alloys. Science 362, 933-937. https://doi.org/ $10.1126 /$ science.aas 8815 .

Yasnikov, I.S., Estrin, Y., Vinogradov, A., 2017. What governs ductility of ultrafine-grained metals? A microstructure based approach to necking instability. Acta Mater. 141, 18-28. https://doi.org/10.1016/j.actamat.2017.08.069.

Yasnikov, I.S., Vinogradov, A., Estrin, Y., 2014. Revisiting the Considère criterion from the viewpoint of dislocation theory fundamentals. Scr. Mater. 76, 37-40. https://doi.org/10.1016/j.scriptamat.2013.12.009.

Zhang, J.W., Beyerlein, I.J., Han, W.Z., 2019. Hierarchical 3D nanolayered duplex-phase Zr with high strength, strain hardening, and ductility. Phys. Rev. Lett. 122, 255501. https://doi.org/10.1103/PhysRevLett.122.255501.

Zhang, Y., Liu, J.P., Chen, S.Y., Xie, X., Liaw, P.K., Dahmen, K.A., Qiao, J.W., Wang, Y.L., 2017. Serration and noise behaviors in materials. Prog. Mater. Sci. 90, 358-460. https://doi.org/10.1016/j.pmatsci.2017.06.004. 
Zhang, T.W., Ma, S.G., Zhao, D., Wu, Y.C., Zhang, Y., Wang, Z.H., Qiao, J.W., 2020. Simultaneous enhancement of strength and ductility in a NiCoCrFe high-entropy alloy upon dynamic tension: Micromechanism and constitutive modeling. Int. J. Plasticity 124, 226-246. https://doi.org/10.1016/j.ijplas.2019.08.013.

Zhao, Y.H., Guo, Y.Z., Wei, Q., Dangelewicz, A.M., Xu, C., Zhu, Y.T., Langdon, T.G., Zhou, Y.Z., Lavernia, E.J., 2008. Influence of specimen dimensions on the tensile behavior of ultrafine-grained Cu. Scr. Mater. 59, 627-630. https://doi.org/10.1016/j.scriptamat.2008.05.031. Zhao, Y.H., Guo, Y.Z., Wei, Q., Topping, T.D., Dangelewicz, A.M., Zhu, Y.T., Langdon, T.G., Lavernia, E.J., 2009. Influence of specimen dimensions and strain measurement methods on tensile stress-strain curves. Mater. Sci. Eng. A 525, 68-77. https://doi.org/10.1016/j.msea.2009.06.031.

Zhao, L., Guo, Q., Li, Z., Li, Z.Q., Fan, G.L., Xiong, D.B., Su, Y.S., Zhang, J., Tan, Z.Q., Zhang, D., 2018. Strain-rate dependent deformation mechanism of graphene-Al nanolaminated composites studied using micro-pillar compression. Int. J. Plasticity 105, 128-140. https://doi.org/10.1016/j.ijplas.2018.02.006.

Zhao, Y.H., Liao, X.Z., Cheng, S., Ma, E., Zhu, Y.T., 2006. Simultaneously increasing the ductility and strength of nanostructured alloys. Adv. Mater. 18, 2280-2283. https://doi.org/10.1002/adma.200600310.

Zhong, S.Y., Ribis, J., Lochet, N., de Carlan, Y., Klosek, V., Mathon, M.H., 2014. Influence of nano-particle coherency degree on the coarsening resistivity of the nano-oxide particles of Fe-14Cr-1W ODS alloys. J. Nucl. Mater. 455, 618-623. https://doi.org/10.1016/j.jnucmat.2014.08.045. 